\title{
1,9-seco-Bicyclic Polyprenylated Acylphloroglucinols from Hypericum uralum
}

\author{
Jing-Jing Zhang, Xing-Wei Yang, Xia Liu, Jun-Zeng Ma, Yang Liao, and Gang Xu
}

\section{Supporting Information}

\section{Contents of Supporting Information}

- The original NMR and MS spectra of compounds 1-6 (Page S2-S25).

- The 1D and 2D NMR spectra of attenuatumione B supplied by authors of Fitoterapia 2014, 95, 1-7 (Page S26-S28). 


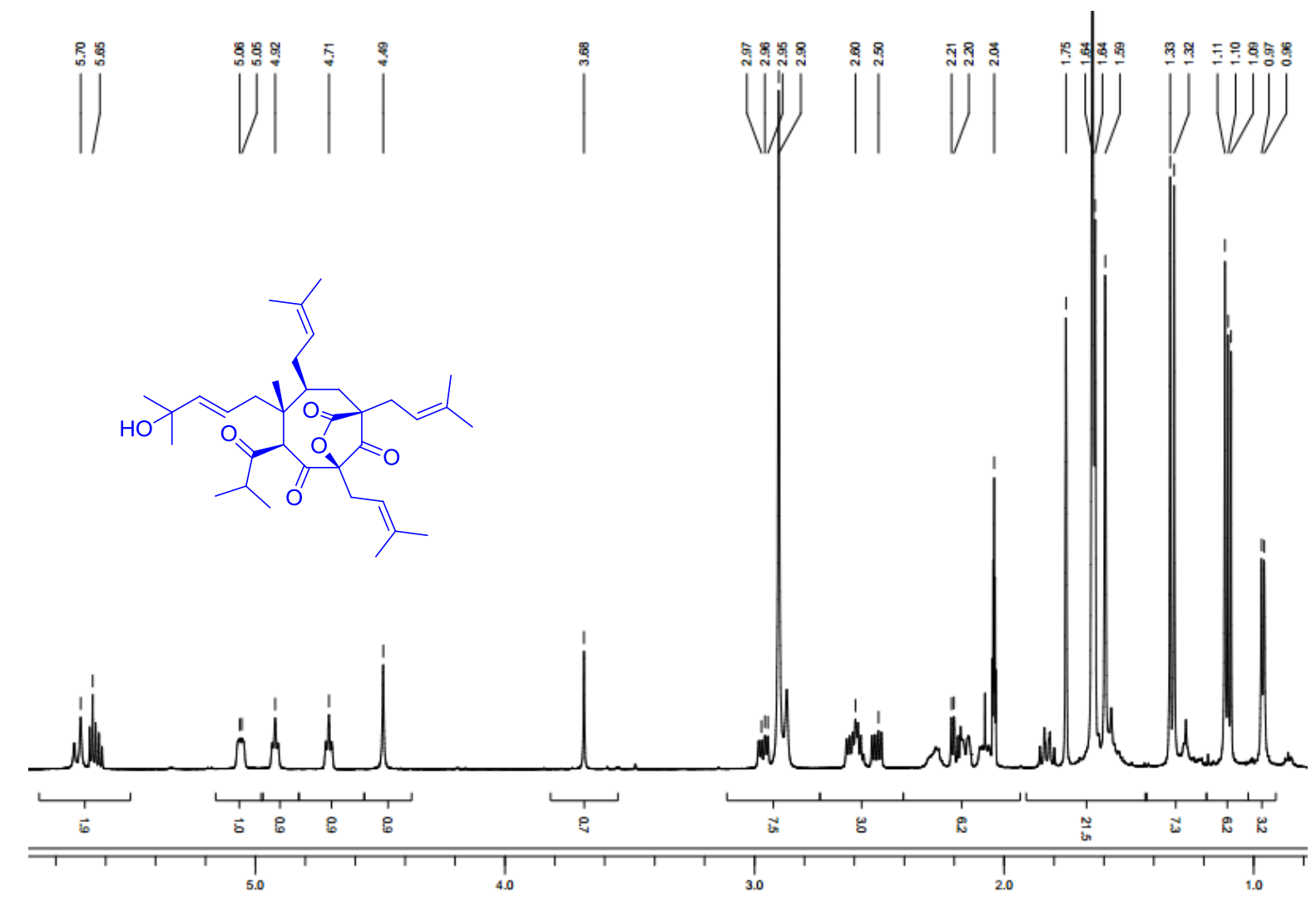

Figure S1. ${ }^{1} \mathrm{H}$ NMR spectrum of hyperuralone C (1) in acetone- $d_{6}$.

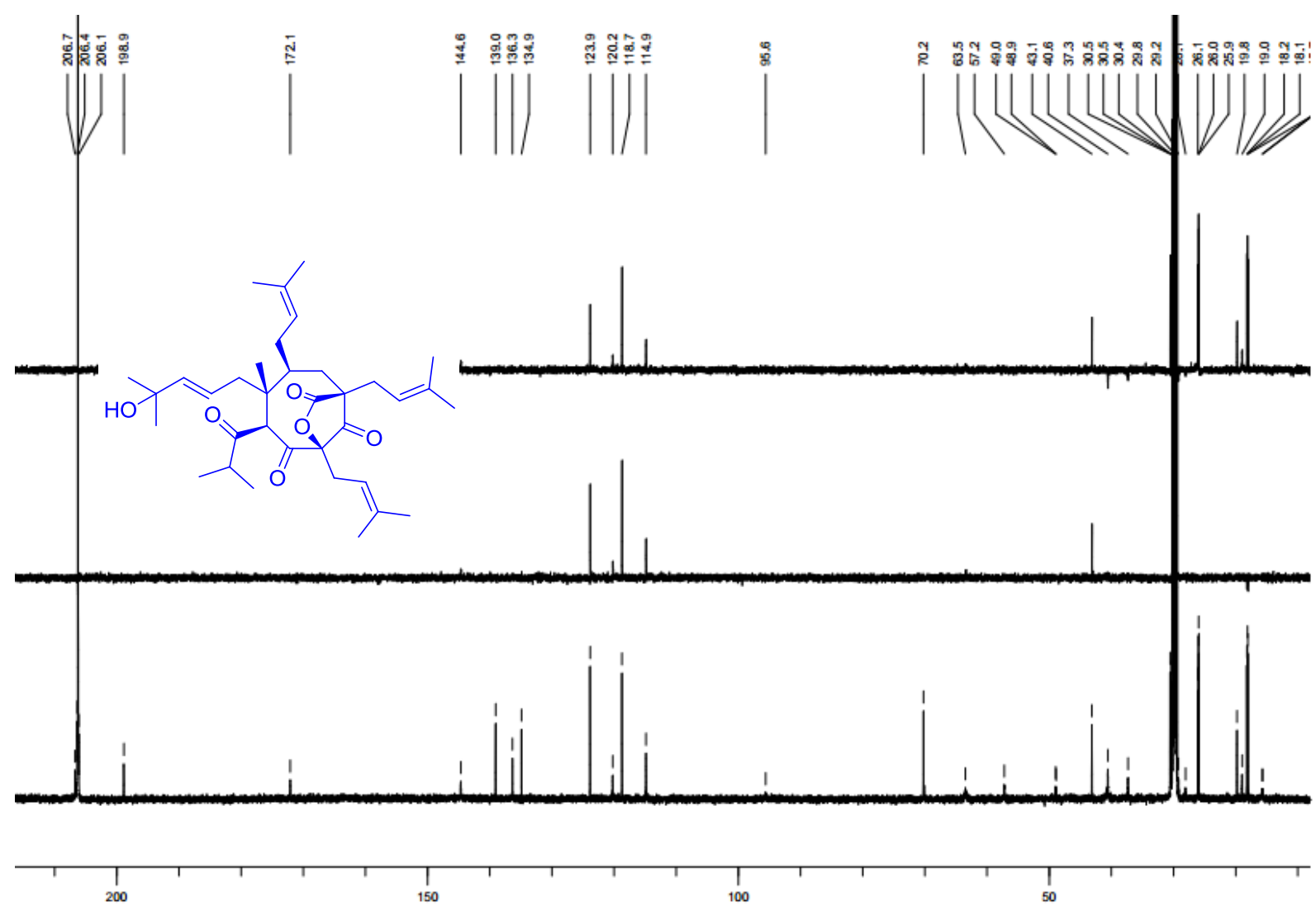

Figure S2. ${ }^{13} \mathrm{C}$ and DEPT NMR spectra of hyperuralone C (1) in acetone- $d_{6}$. 


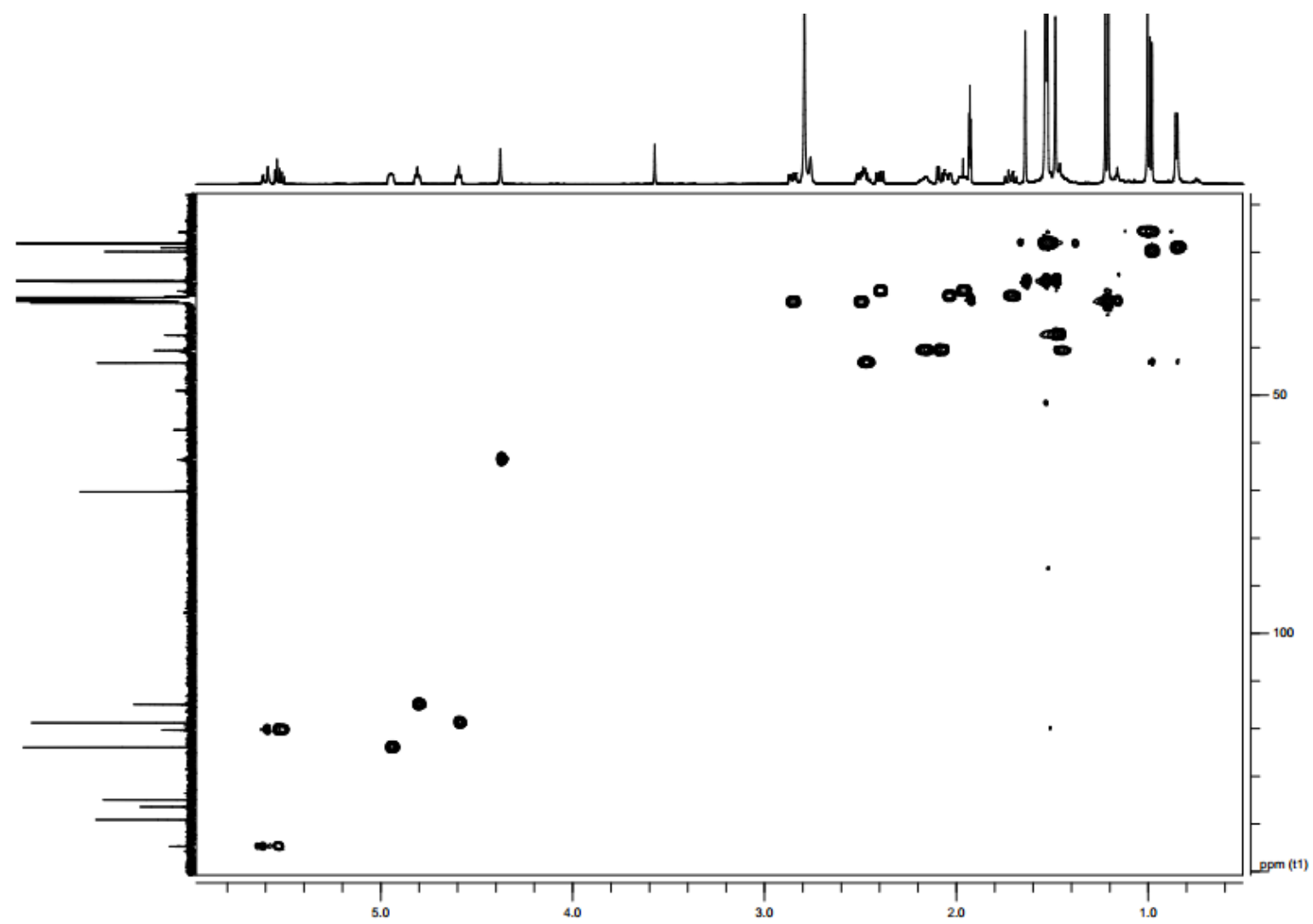

Figure S3. HSQC spectrum of hyperuralone C (1) in acetone- $d_{6}$.

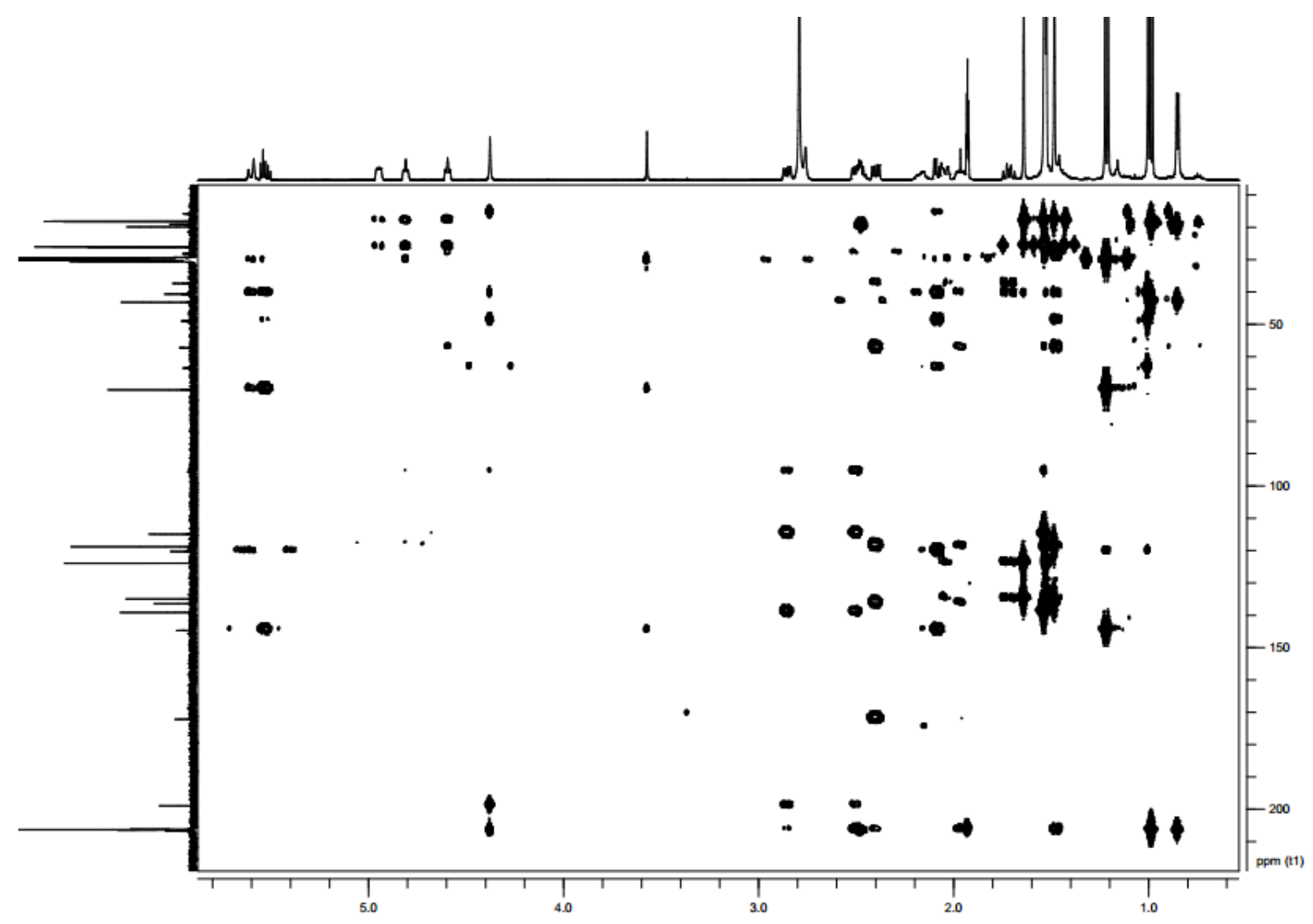

Figure S4. HMBC spectrum of hyperuralone C (1) in acetone- $d_{6}$. 


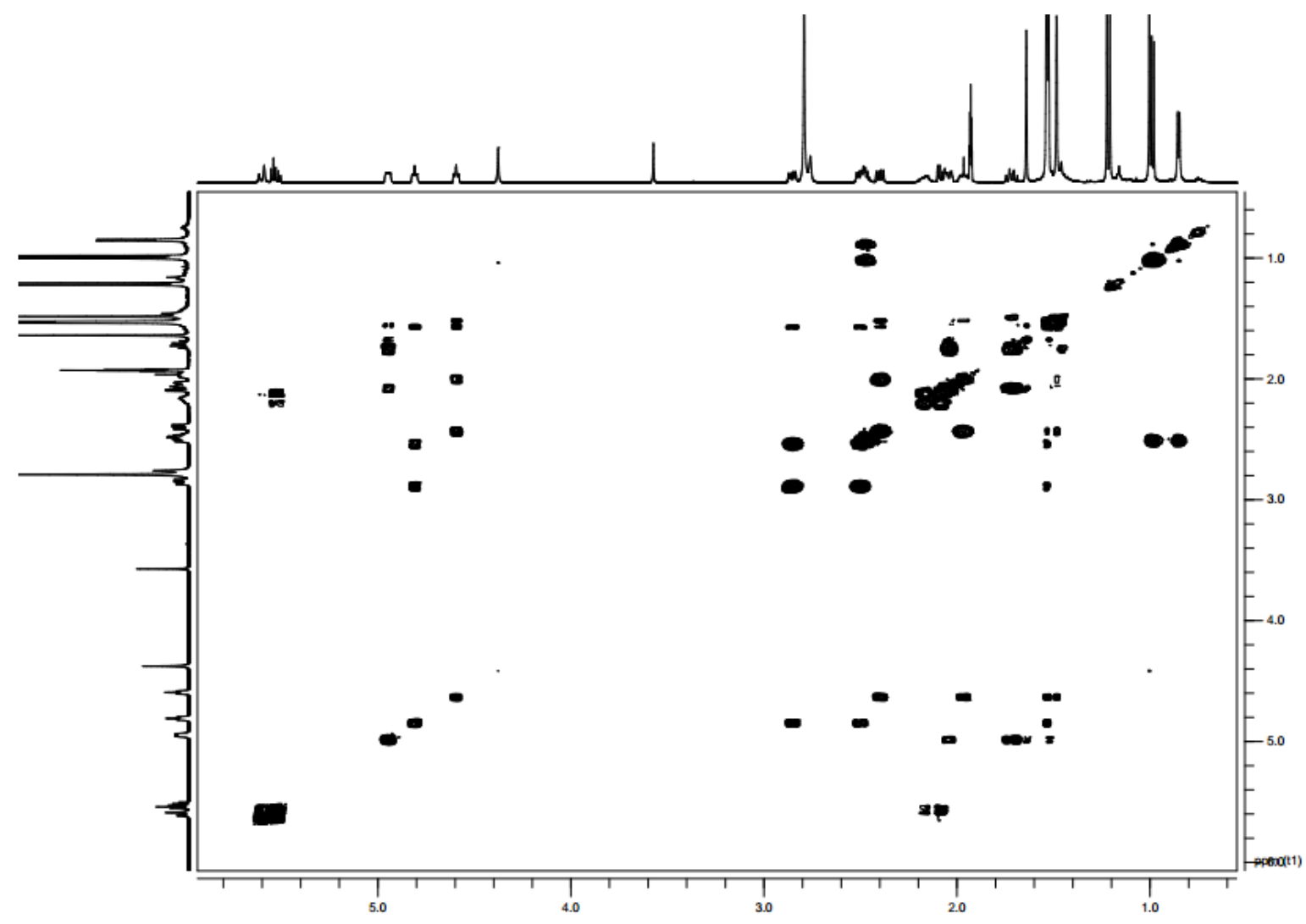

Figure S5. ${ }^{1} \mathrm{H}-{ }^{1} \mathrm{H}$ COSY spectrum of hyperuralone C (1) in acetone- $d_{6}$.

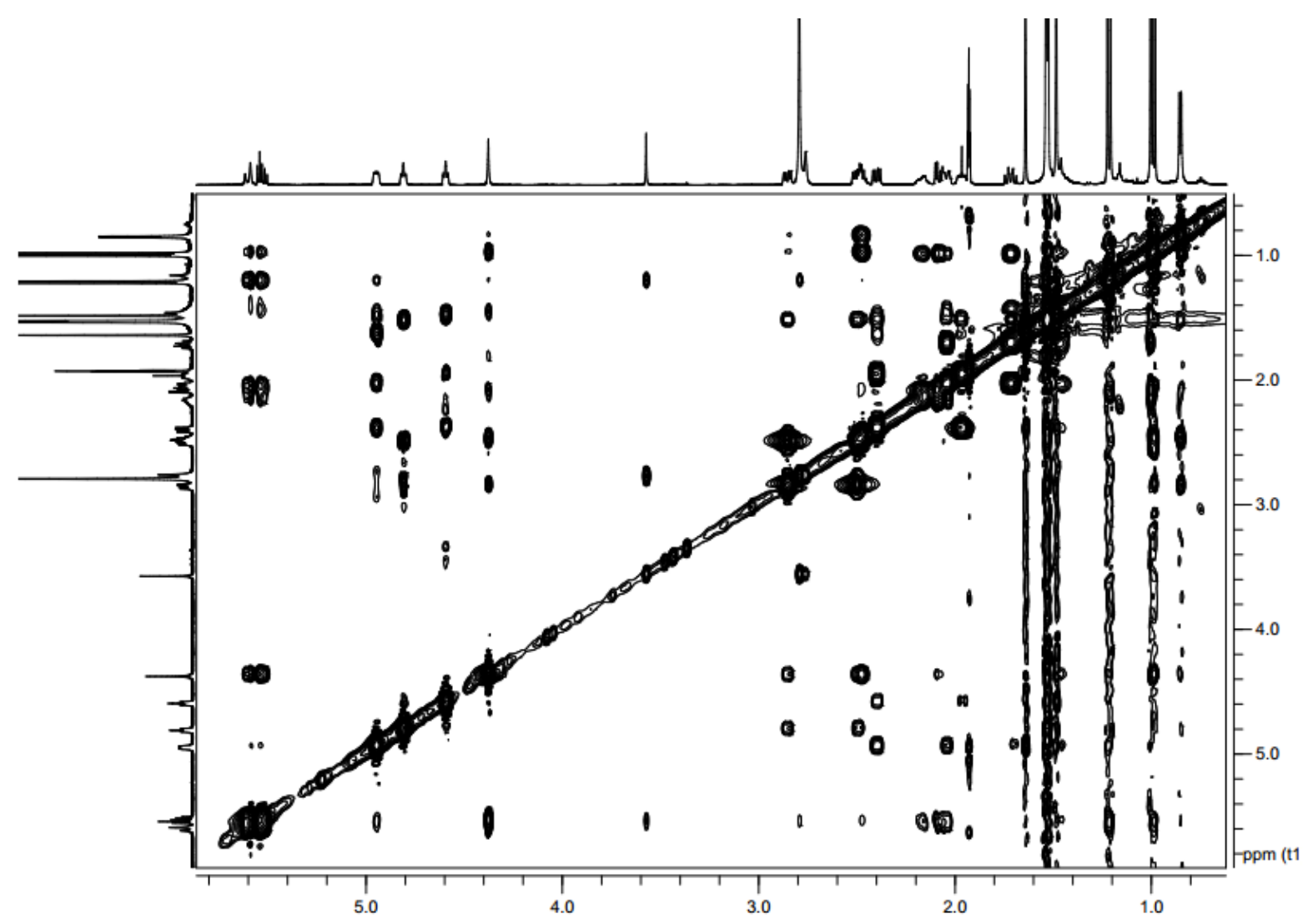

Figure S6. ROESY spectrum of hyperuralone C (1) in acetone- $d_{6}$. 


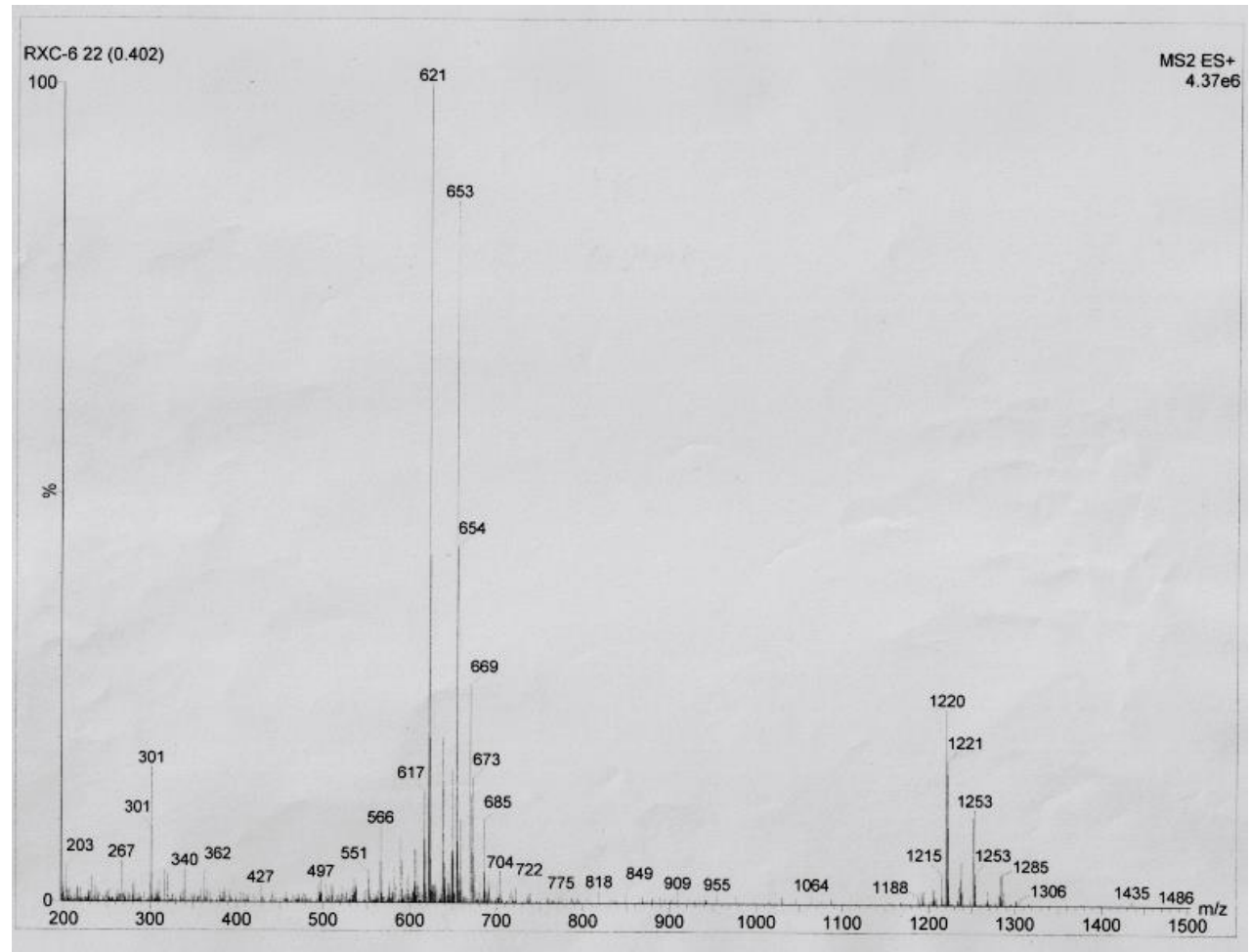

Figure S7. ESIMS spectrum of hyperuralone C (1).

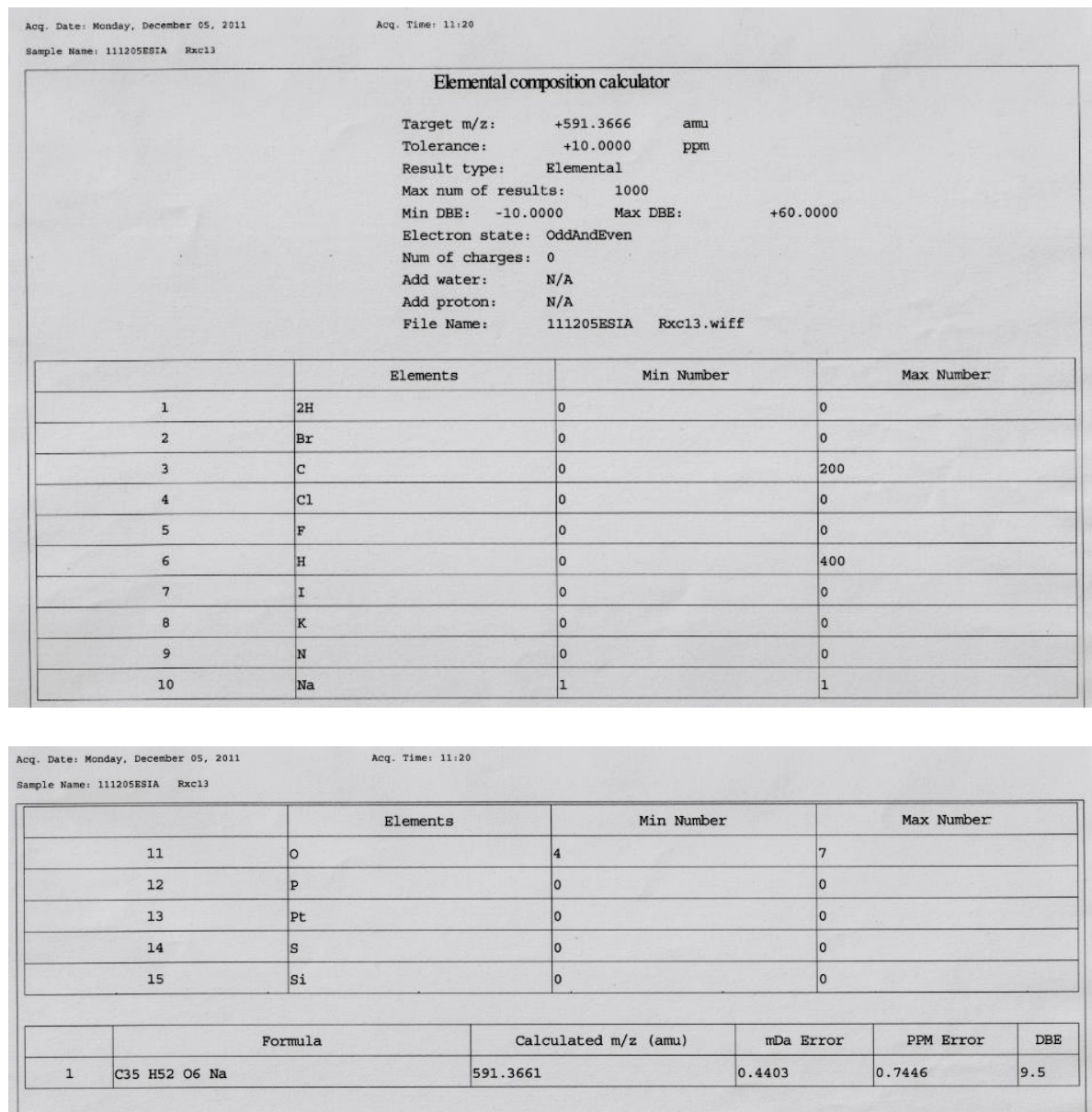

Figure S8. HRTOFMS spectroscopic report of hyperuralone C (1). 


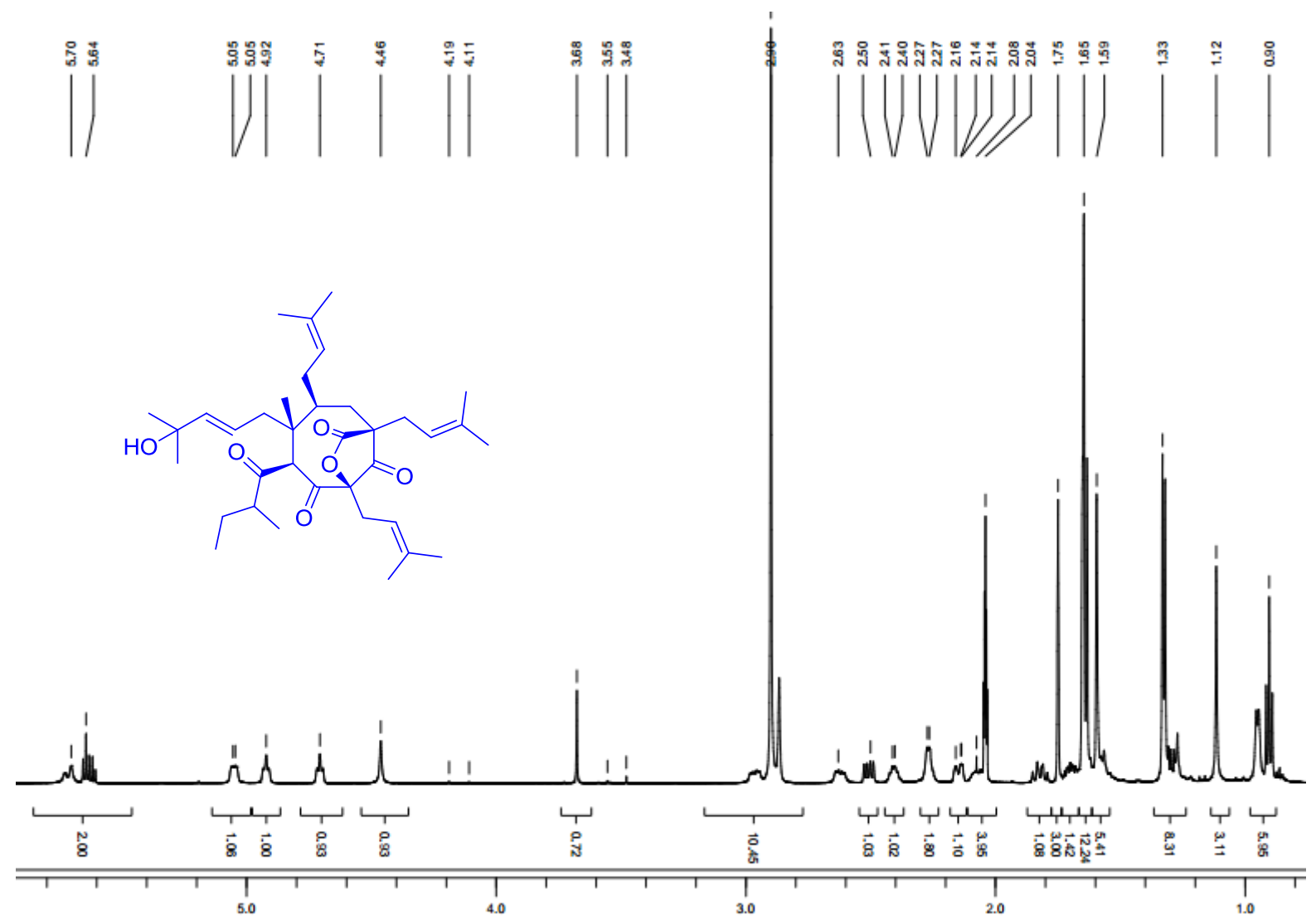

Figure S9. ${ }^{1} \mathrm{H}$ NMR spectrum of hyperuralone D (2) in acetone- $d_{6}$.

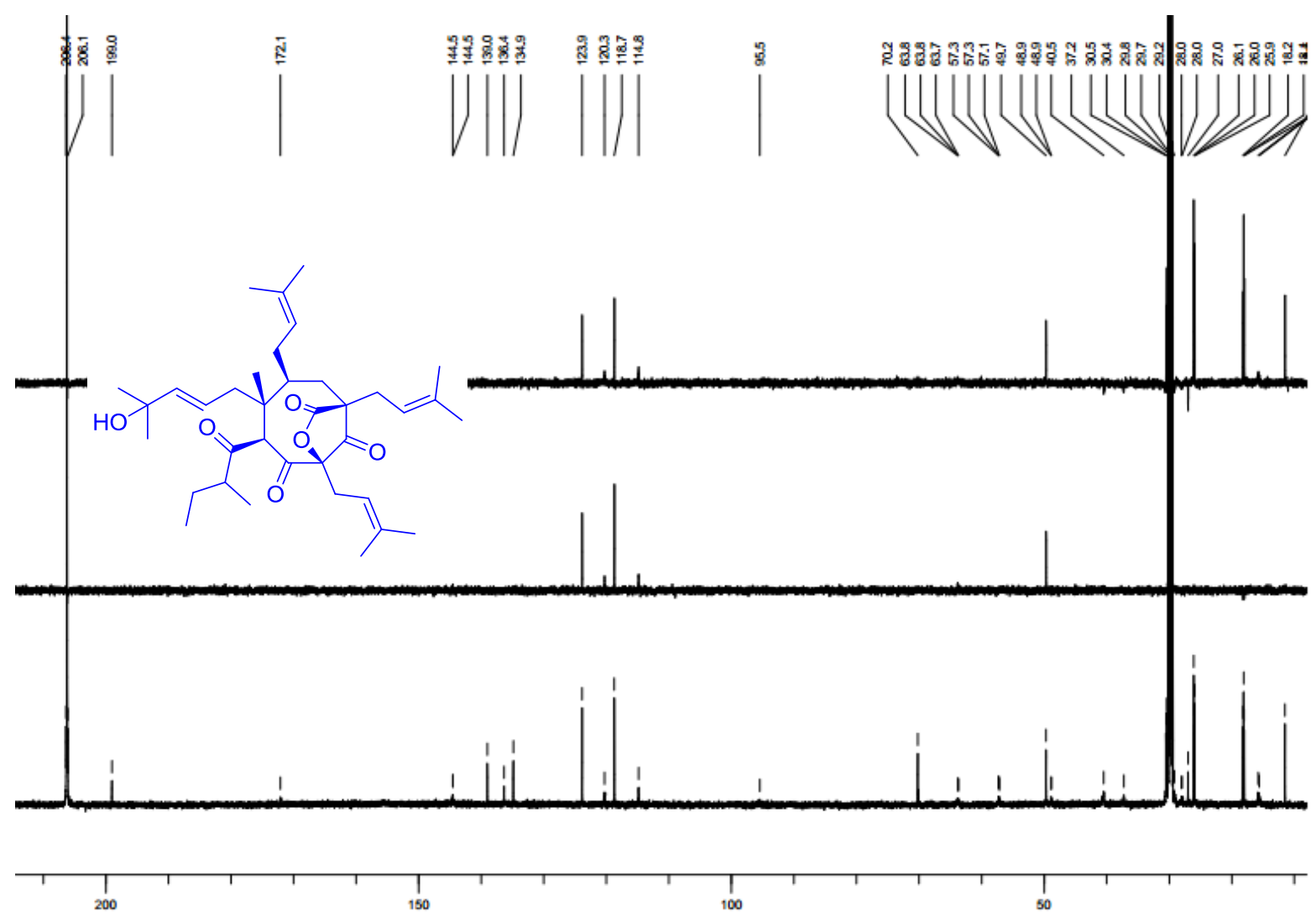

Figure S10. ${ }^{13} \mathrm{C}$ and DEPT NMR spectra of hyperuralone D (2) in acetone- $d_{6}$. 


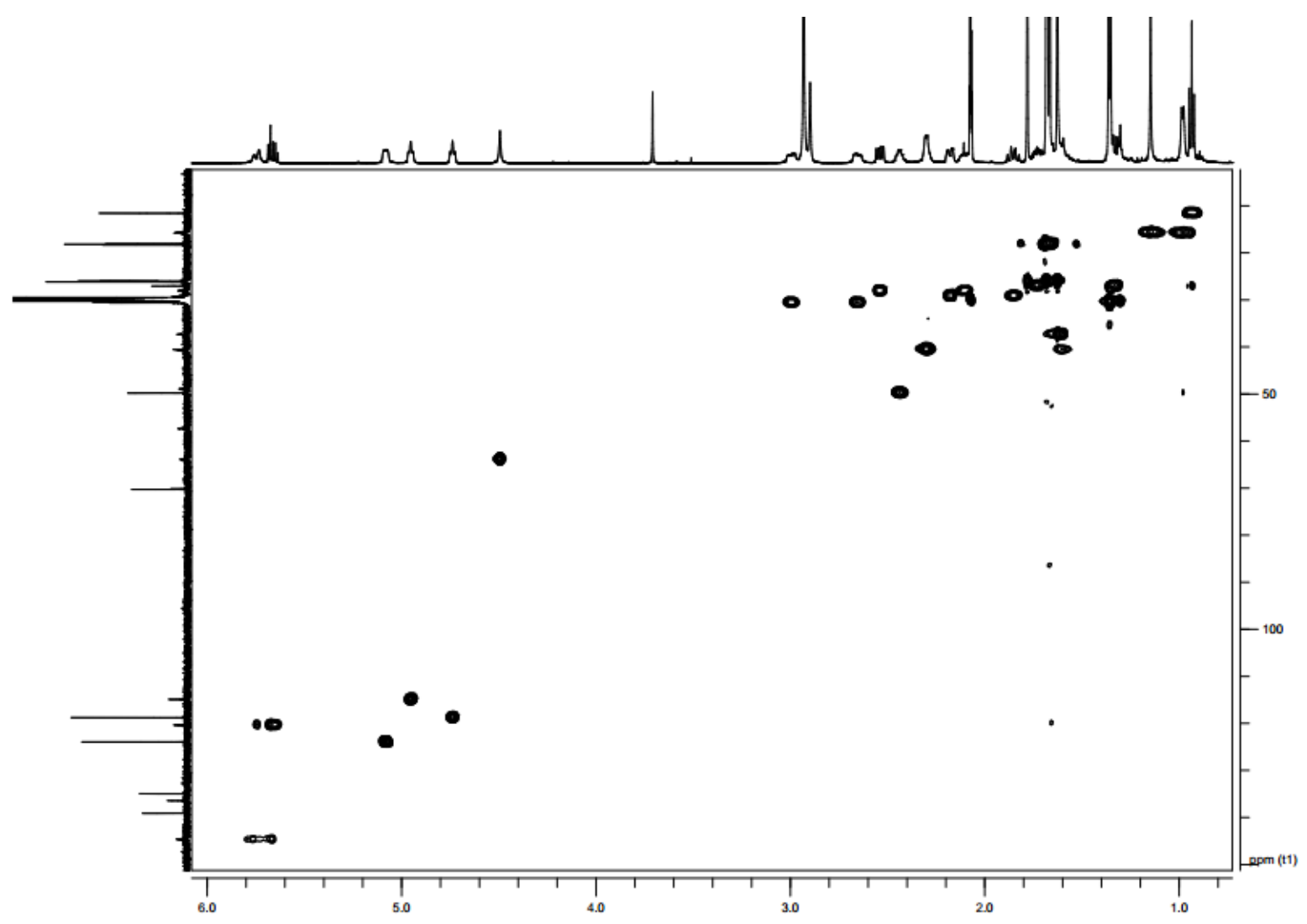

Figure S11. HSQC spectrum of hyperuralone D (2) in acetone- $d_{6}$.

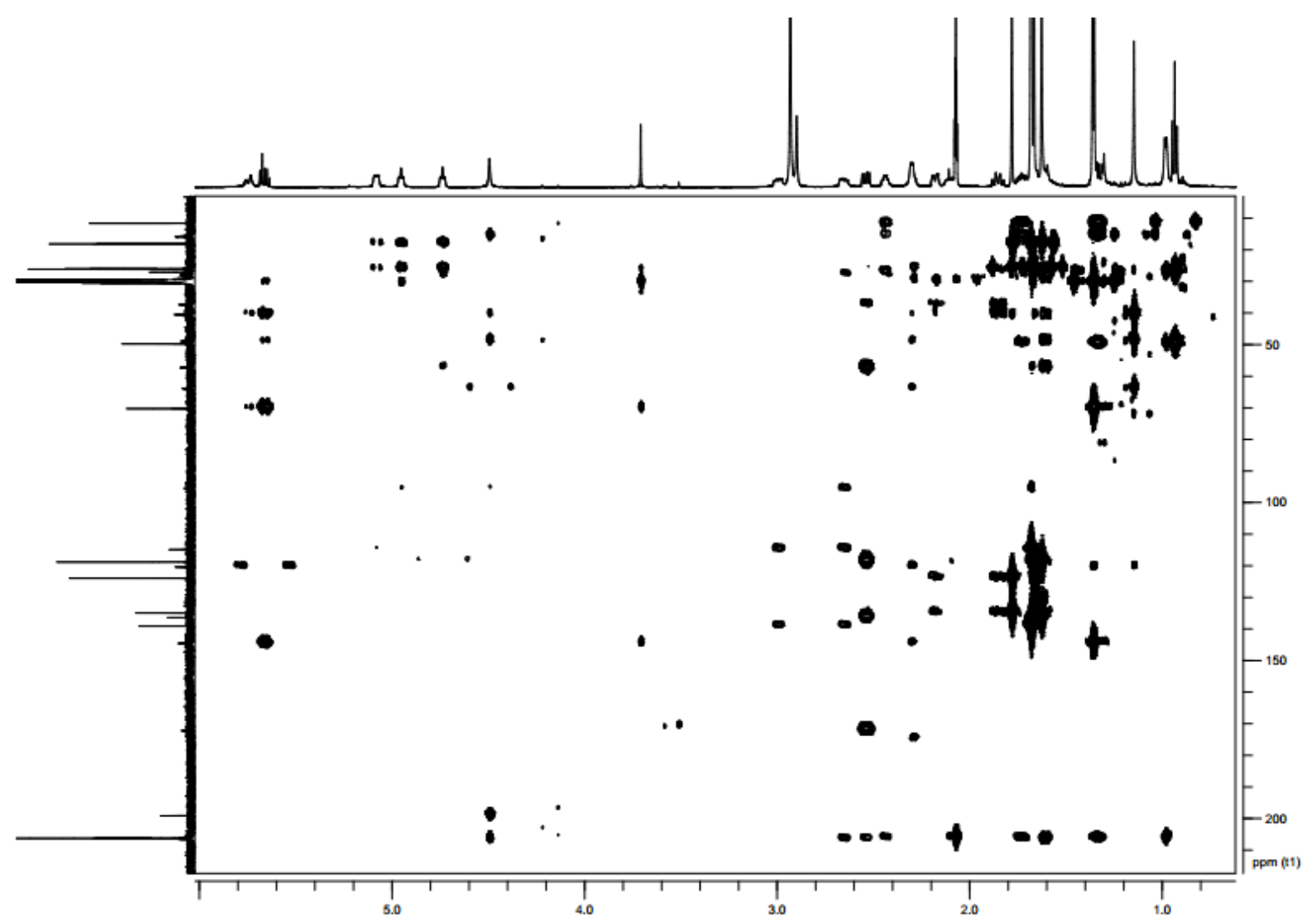

Figure S12. HMBC spectrum of hyperuralone D (2) in acetone- $d_{6}$. 


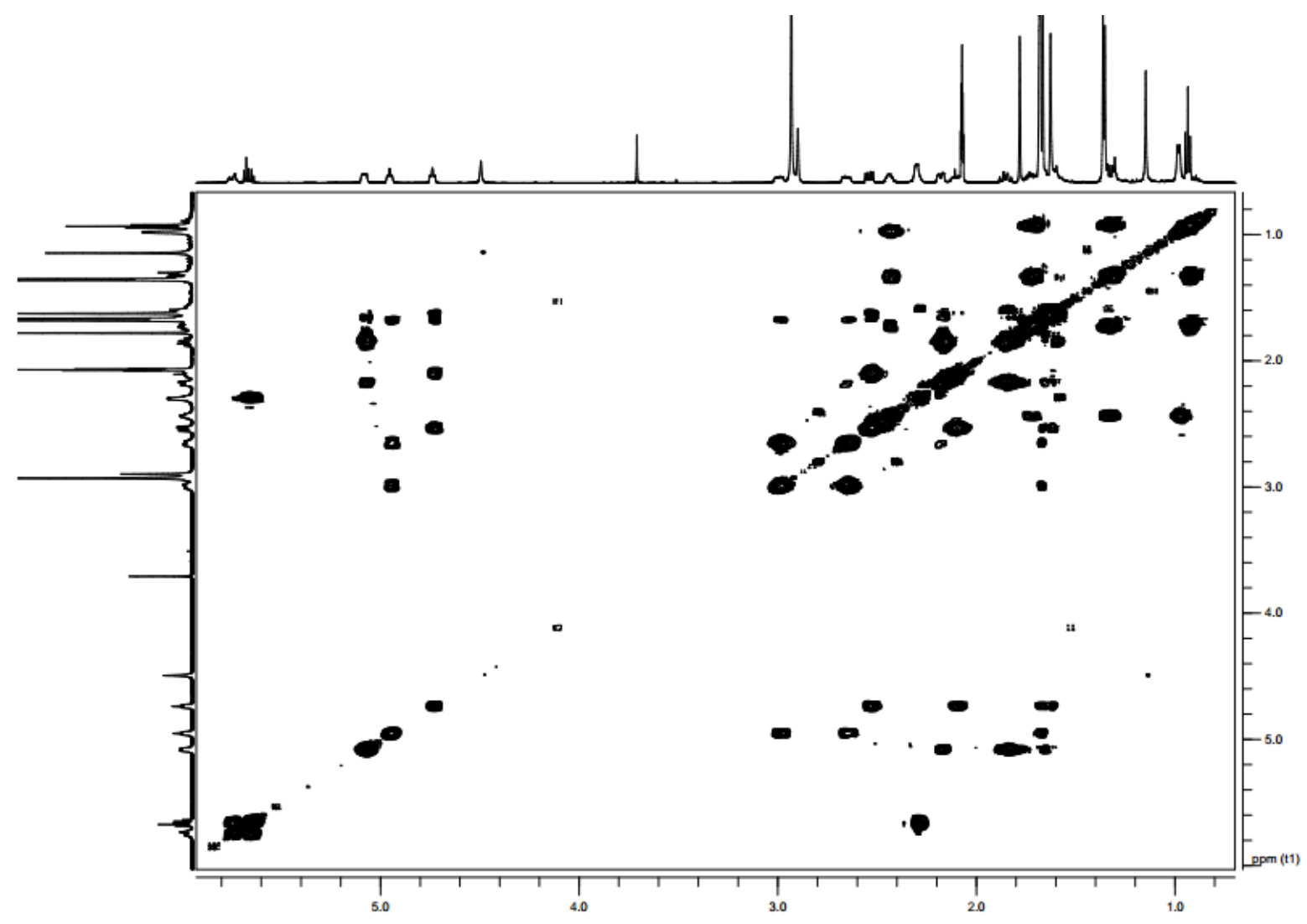

Figure S13. ${ }^{1} \mathrm{H}-{ }^{1} \mathrm{H}$ COSY spectrum of hyperuralone D (2) in acetone- $d_{6}$.

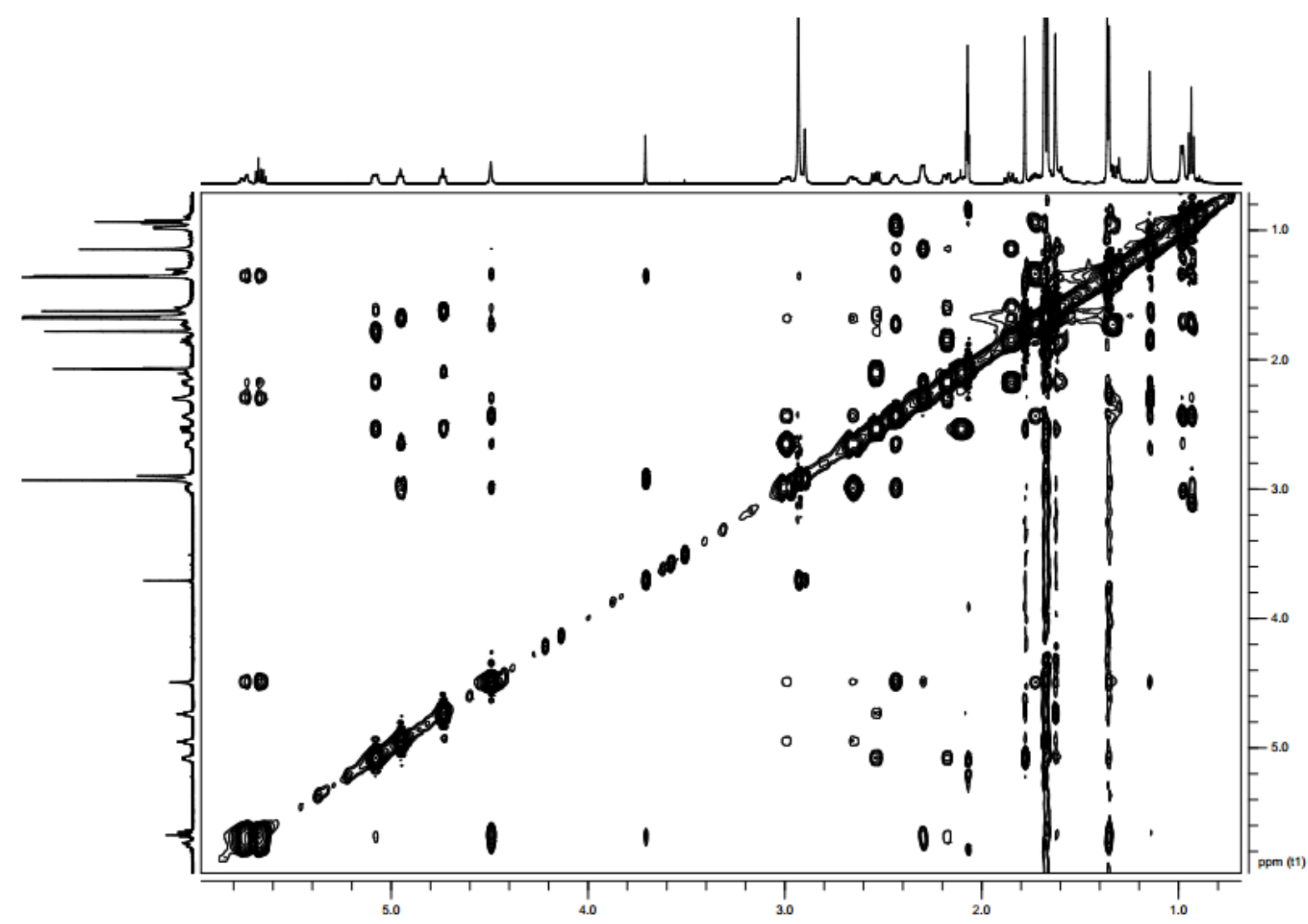

Figure S14. ROESY spectrum of hyperuralone D (2) in acetone- $d_{6}$. 


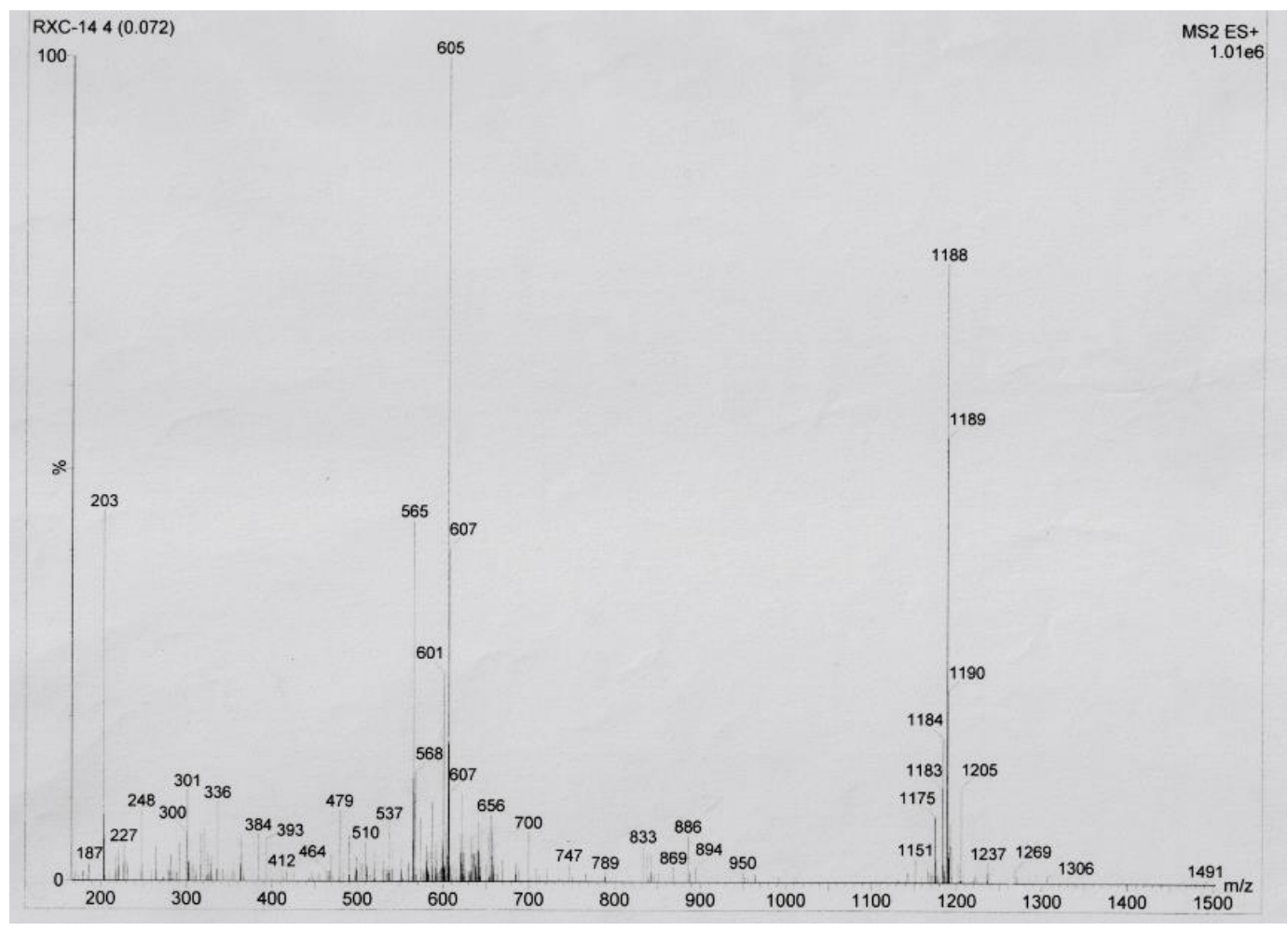

Figure S15. ESIMS spectrum of hyperuralone D (2).

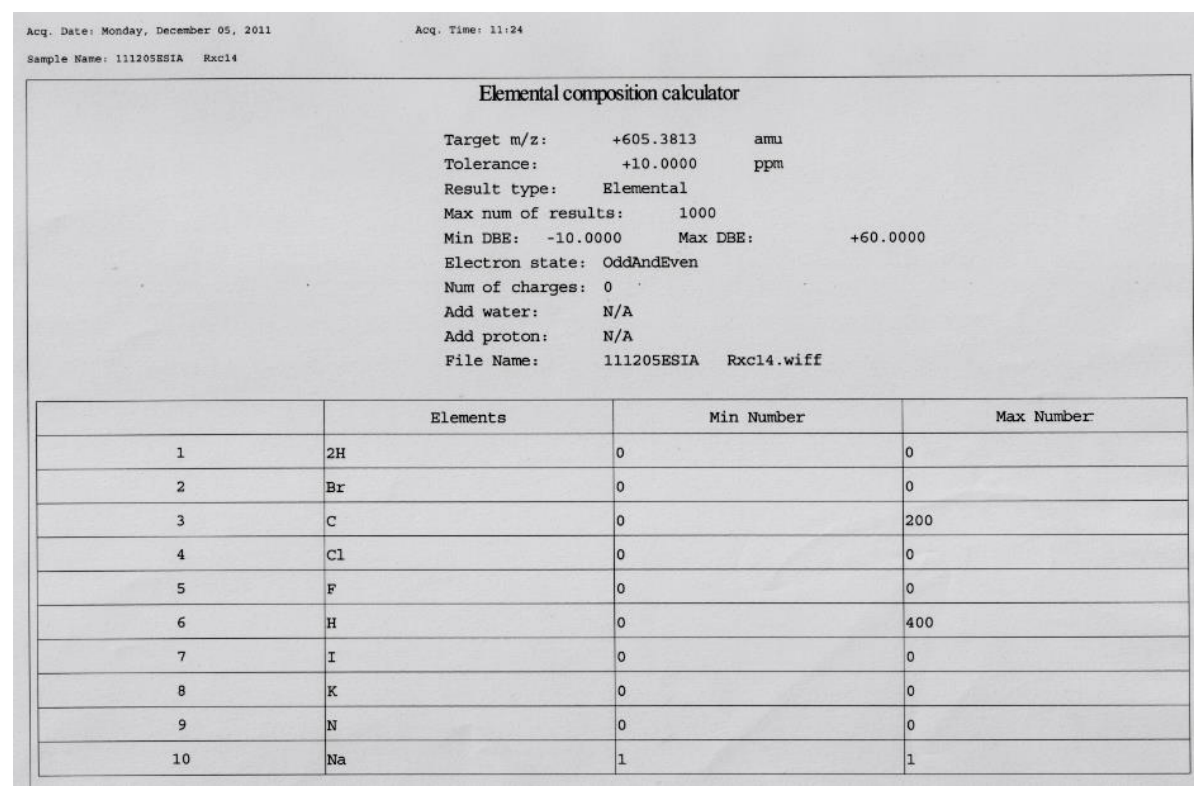

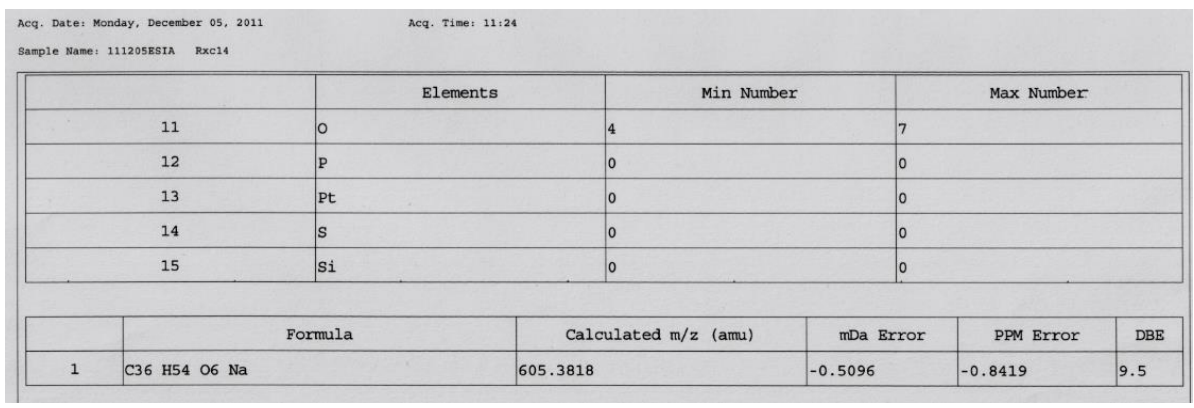

Figure S16. HRTOFMS spectroscopic report of hyperuralone D (2). 


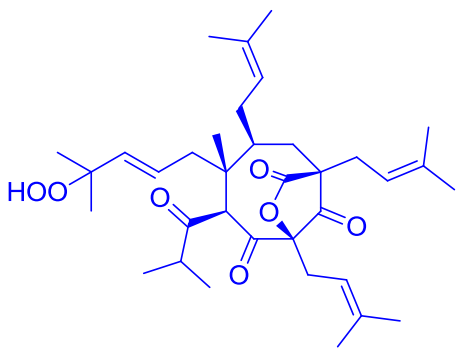

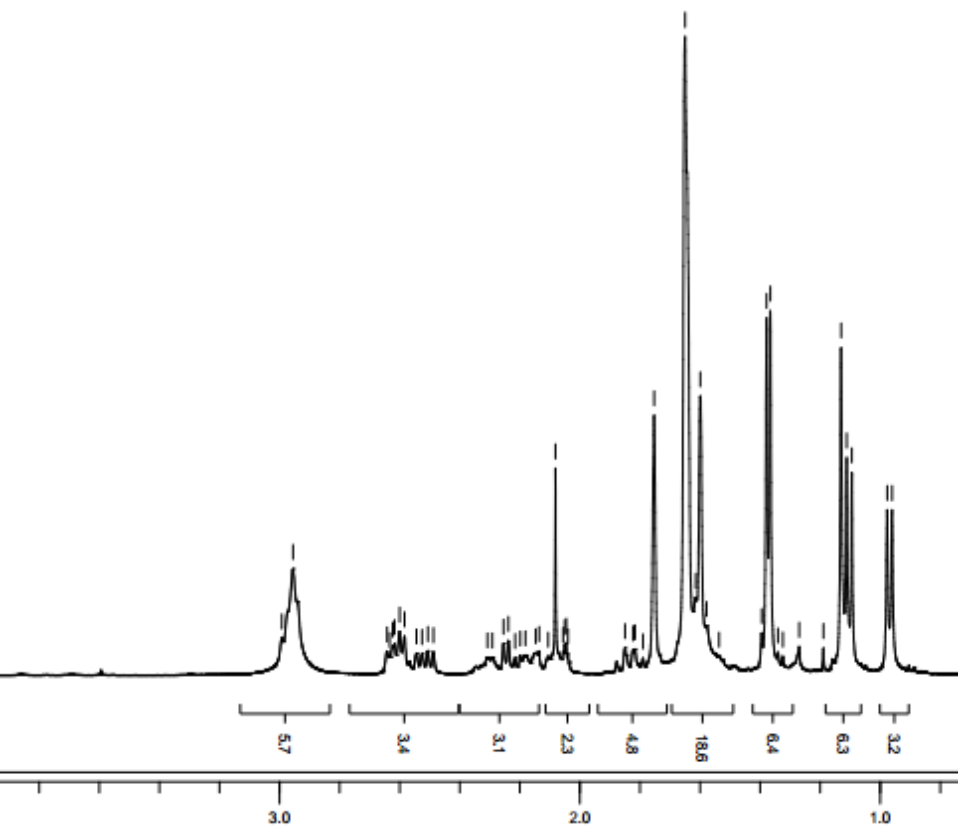

Figure S17. ${ }^{1} \mathrm{H}$ NMR spectrum of hyperuralone E (3) in acetone- $d_{6}$.
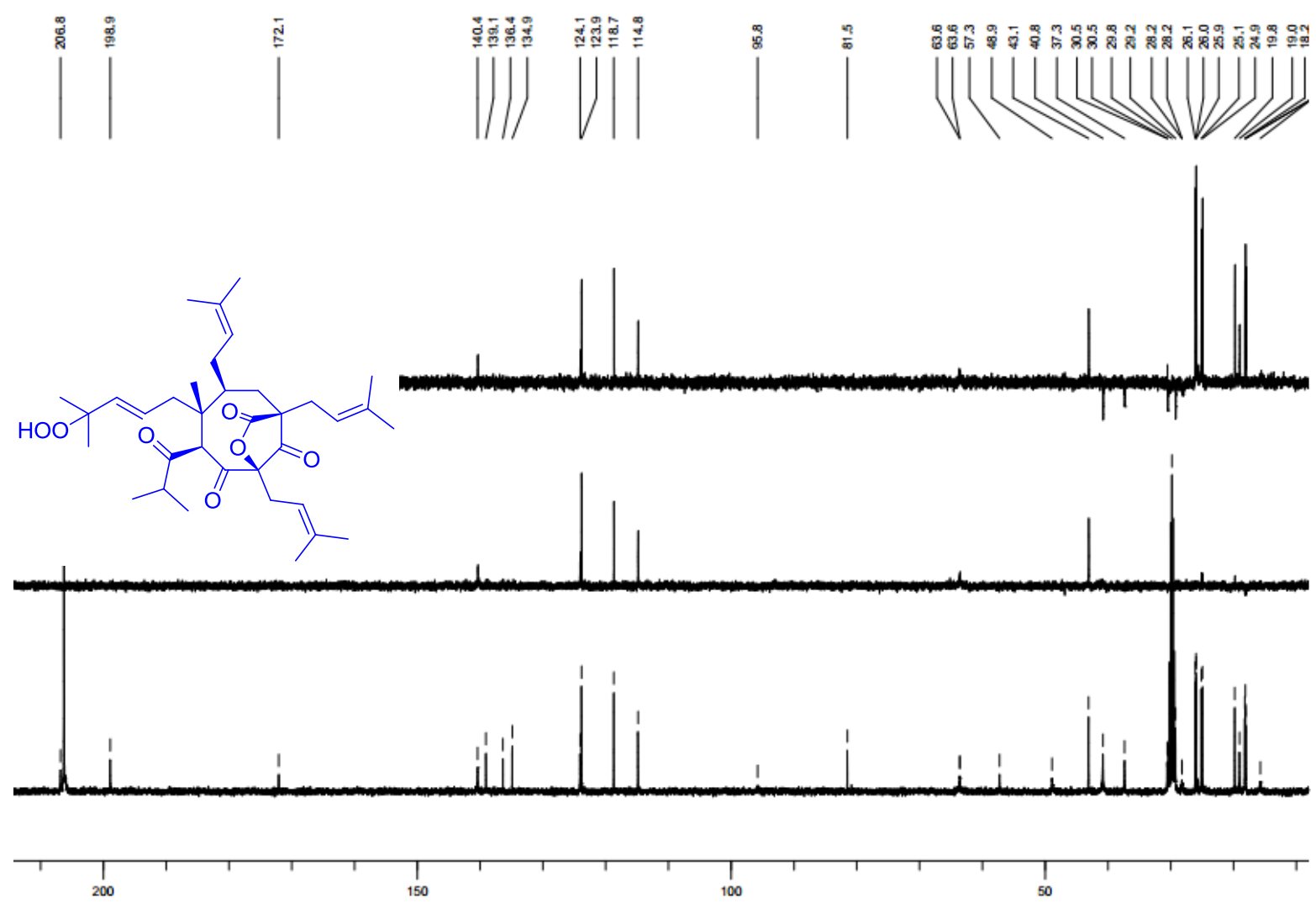

Figure S18. ${ }^{13} \mathrm{C}$ and DEPT NMR spectra of hyperuralone E (3) in acetone- $d_{6}$. 


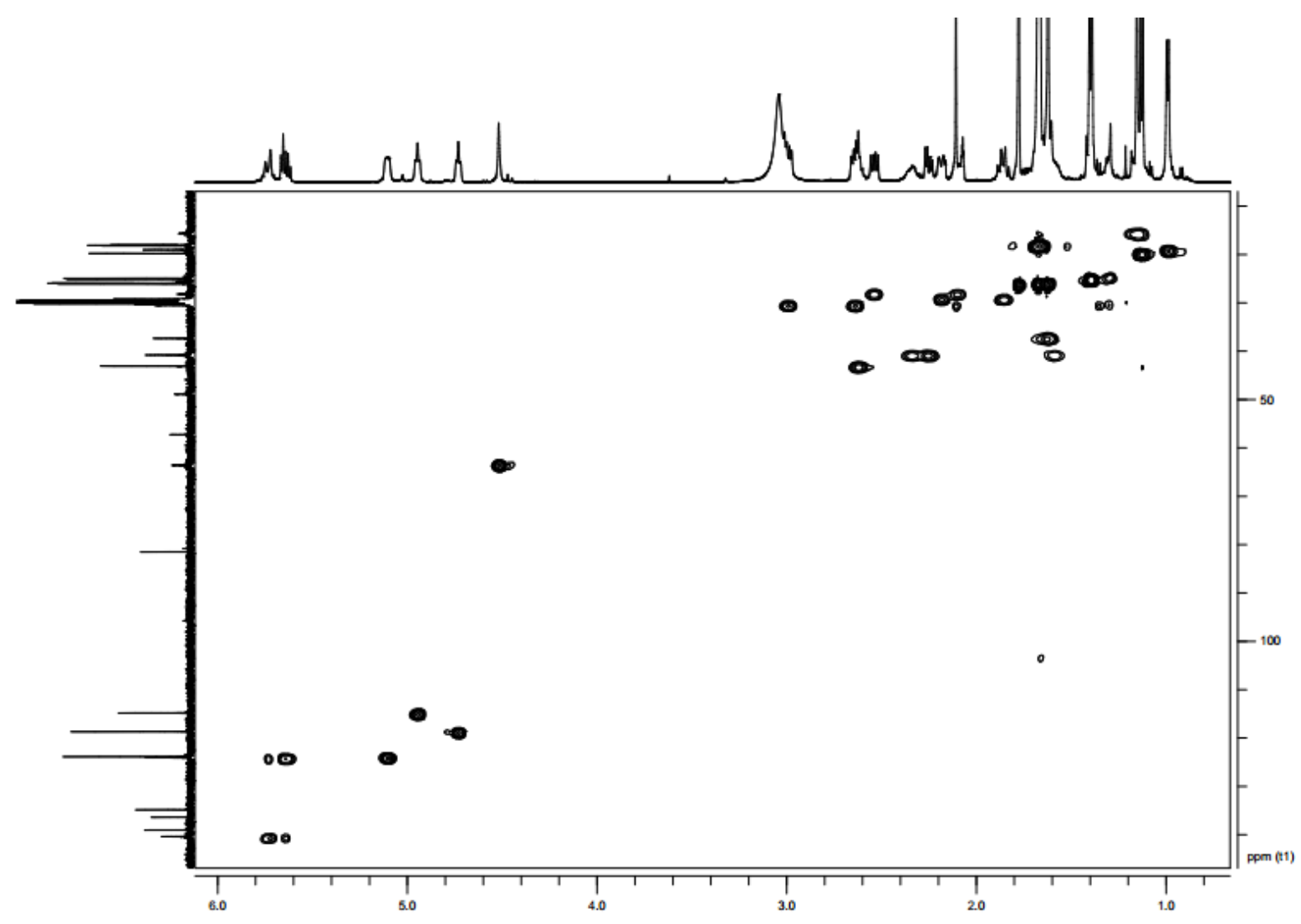

Figure S19. HSQC spectrum of hyperuralone E (3) in acetone- $d_{6}$.

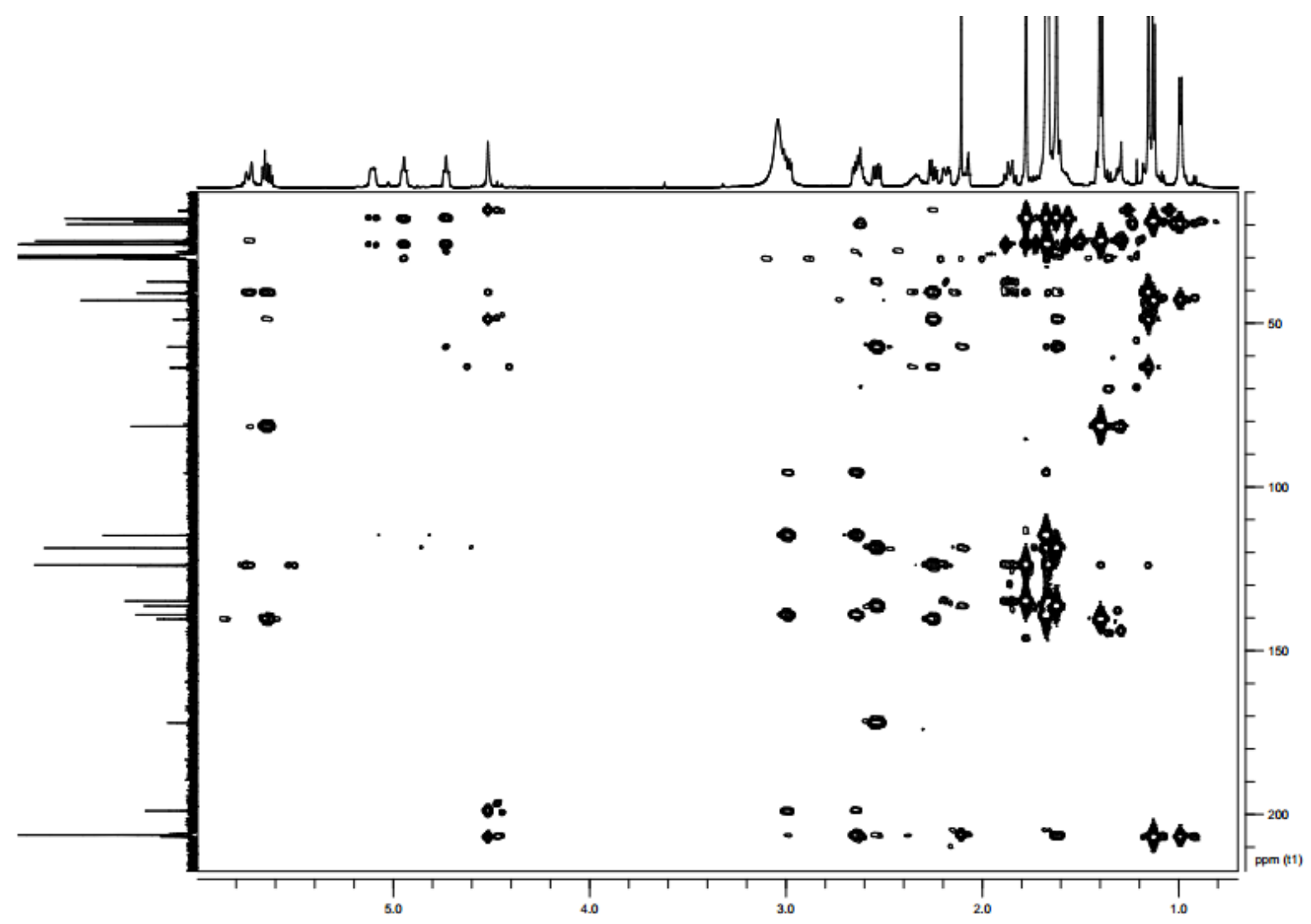

Figure S20. HMBC spectrum of hyperuralone E (3) in acetone- $d_{6}$. 


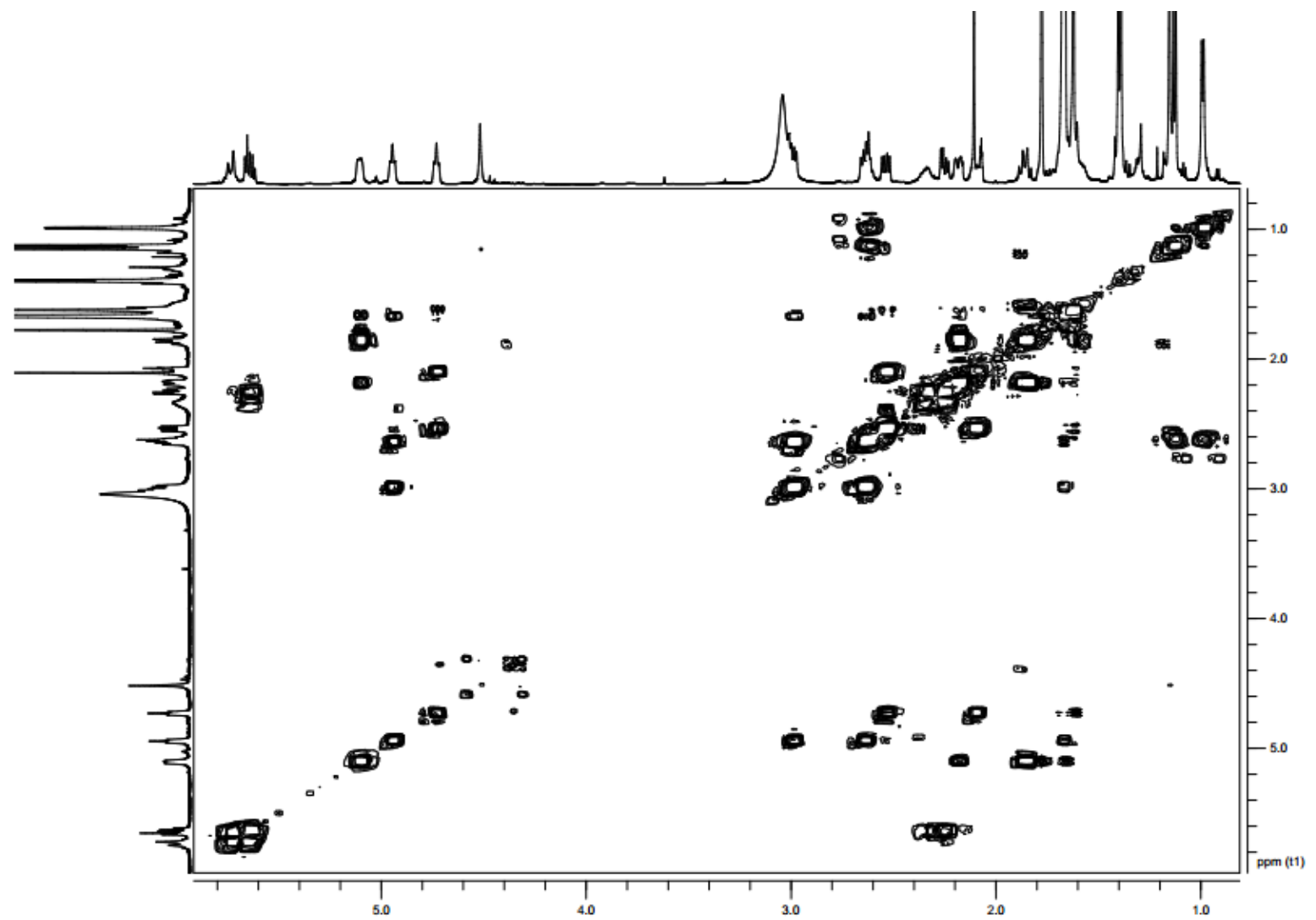

Figure S21. ${ }^{1} \mathrm{H}-{ }^{1} \mathrm{H}$ COSY spectrum of hyperuralone E (3) in acetone- $d_{6}$.

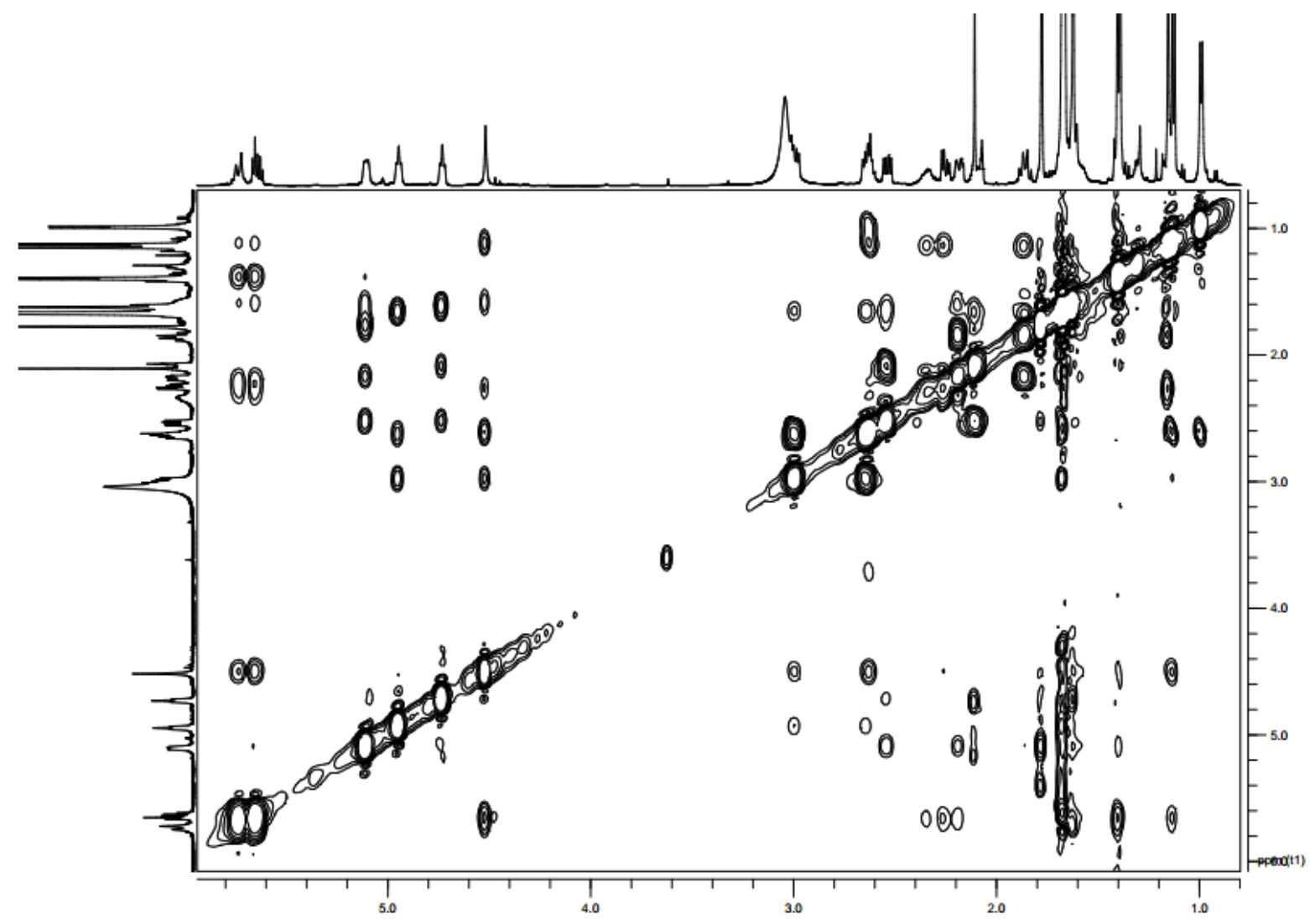

Figure S22. ROESY spectrum of hyperuralone E (3) in acetone- $d_{6}$. 


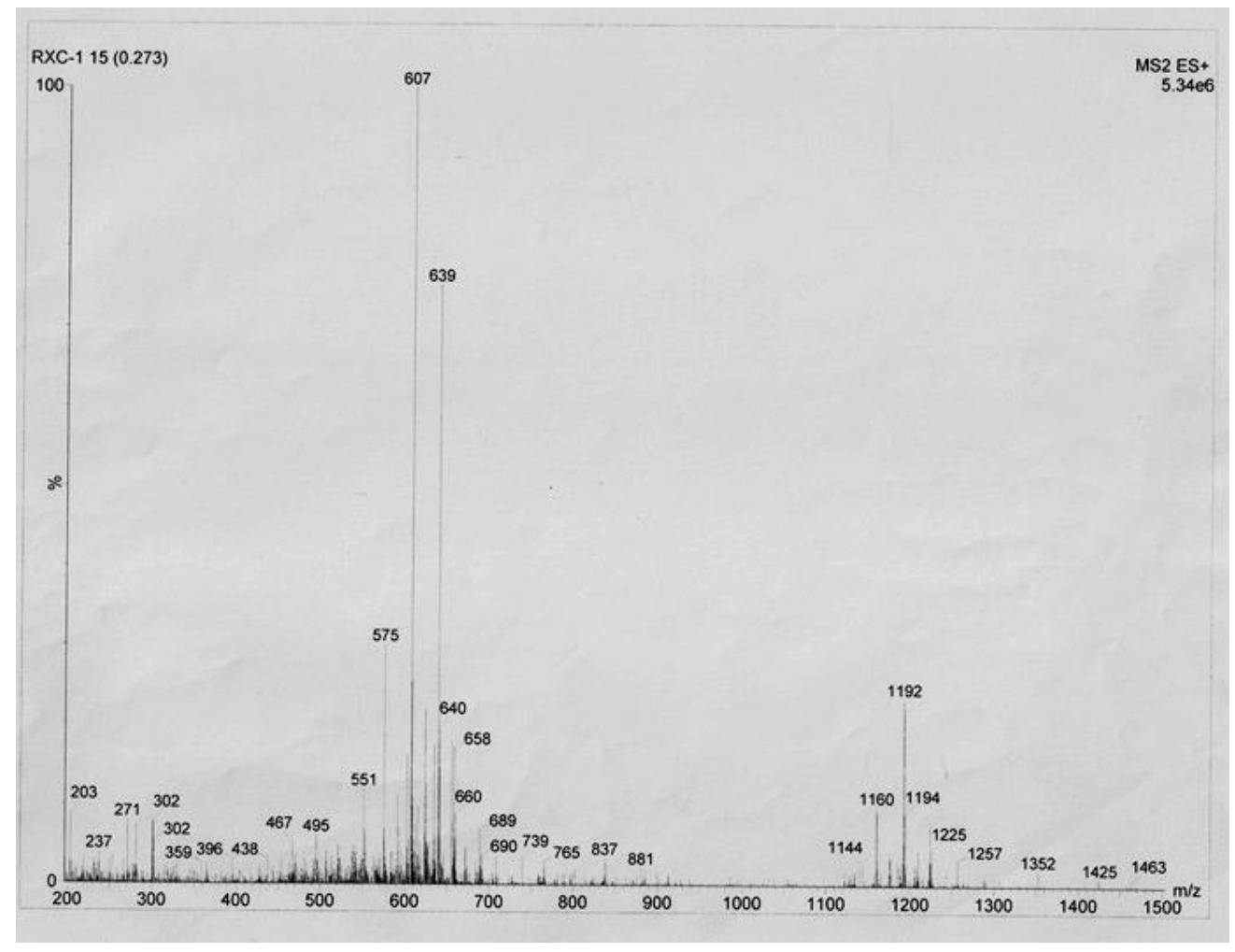

Figure S23. ESIMS spectrum of hyperuralone E (3).

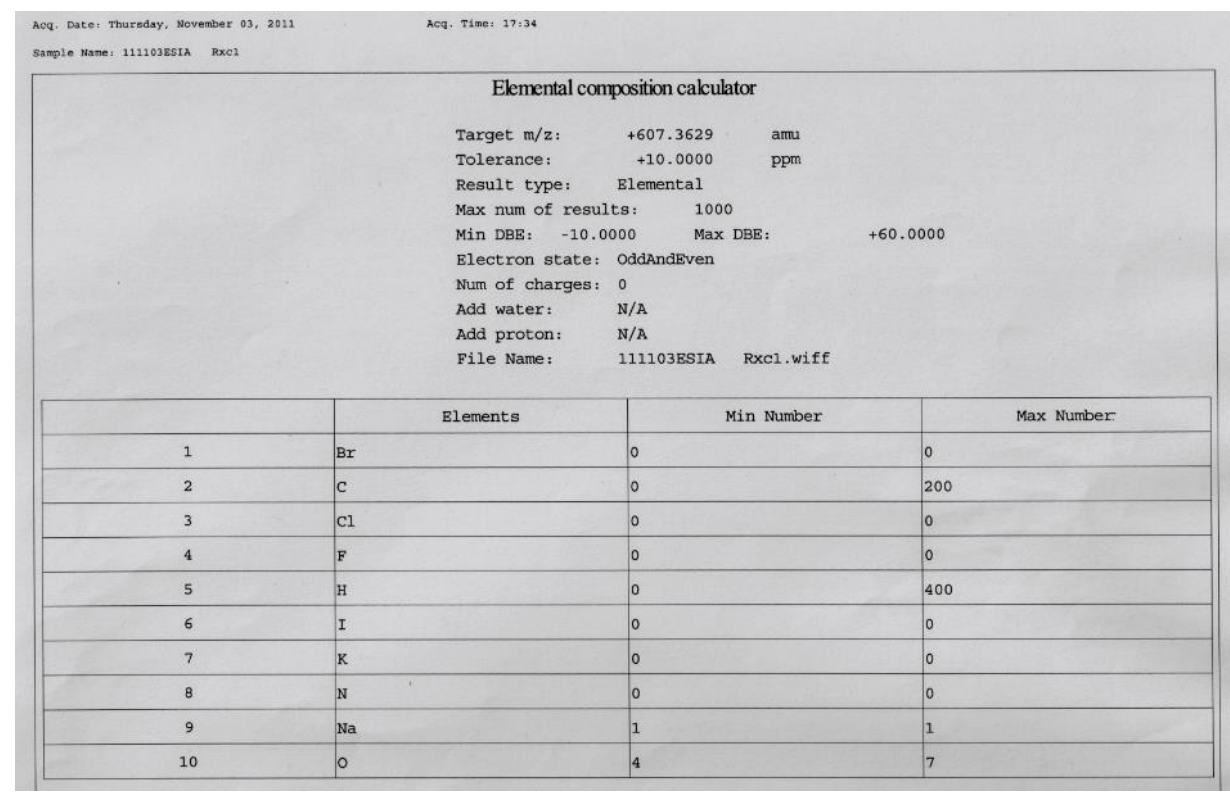

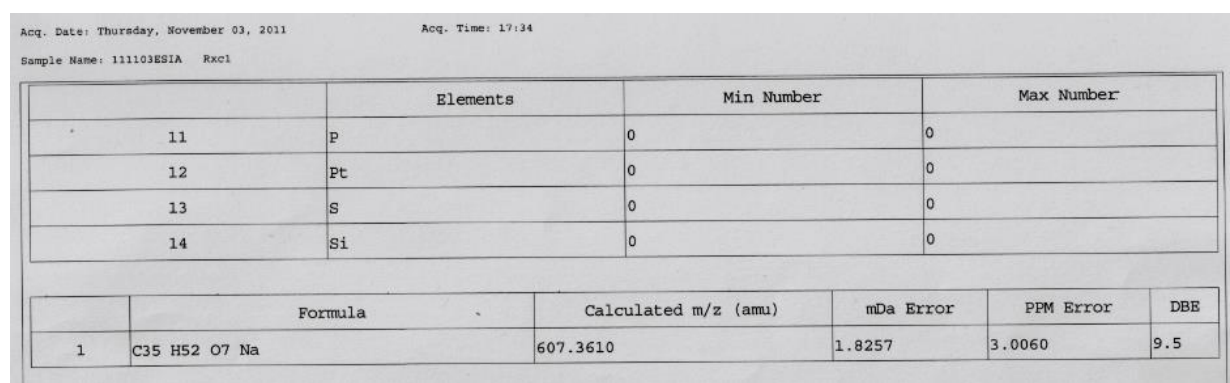

Figure S24. HRTOFMS spectroscopic report of hyperuralone E (3). 


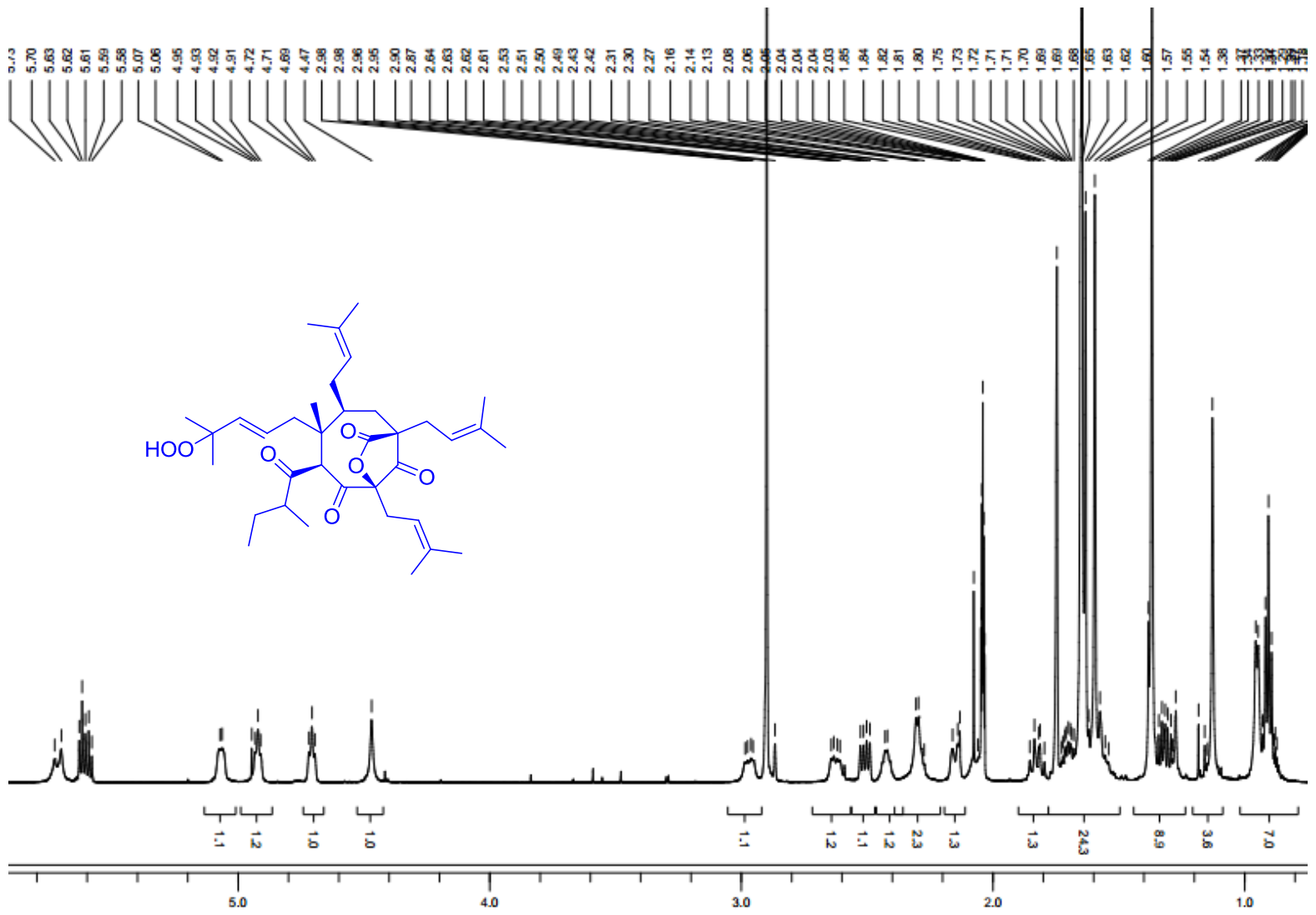

Figure S25. ${ }^{1} \mathrm{H}$ NMR spectrum of hyperuralone F (4) in acetone- $d_{6}$.

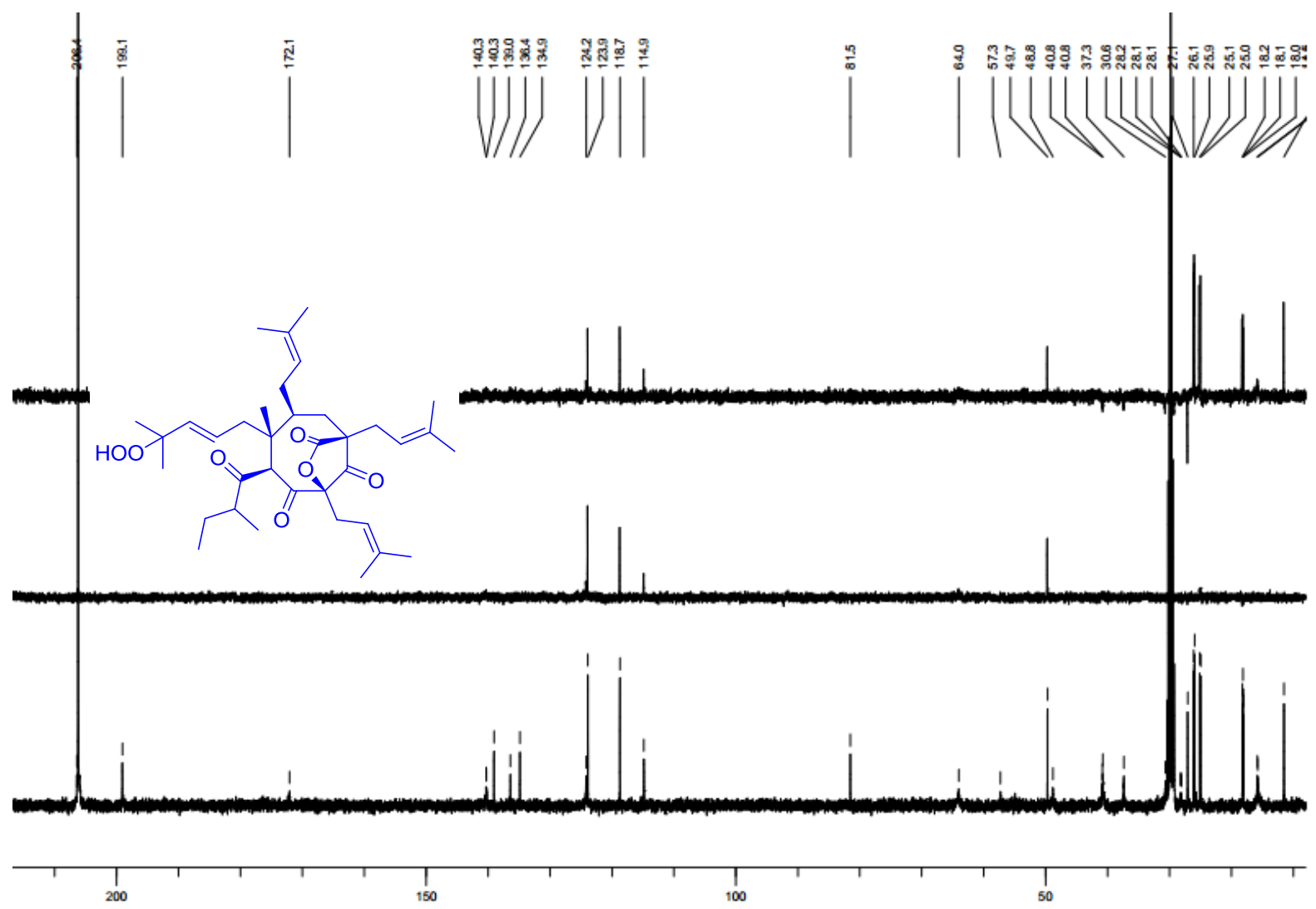

Figure S26. ${ }^{13} \mathrm{C}$ and DEPT NMR spectra of hyperuralone $\mathrm{F}(4)$ in acetone- $d_{6}$. 


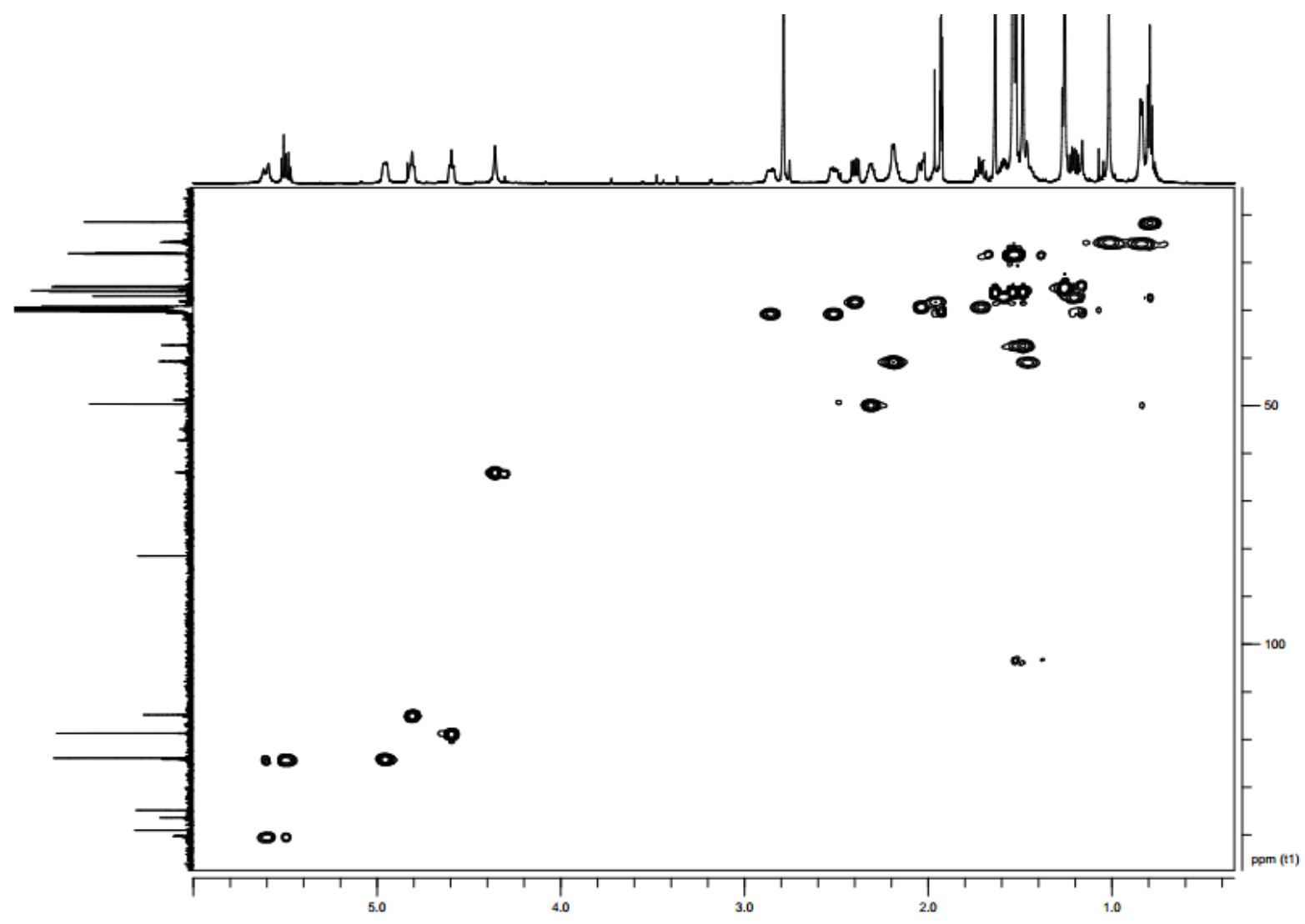

Figure S27. HSQC spectrum of hyperuralone F (4) in acetone- $d_{6}$.

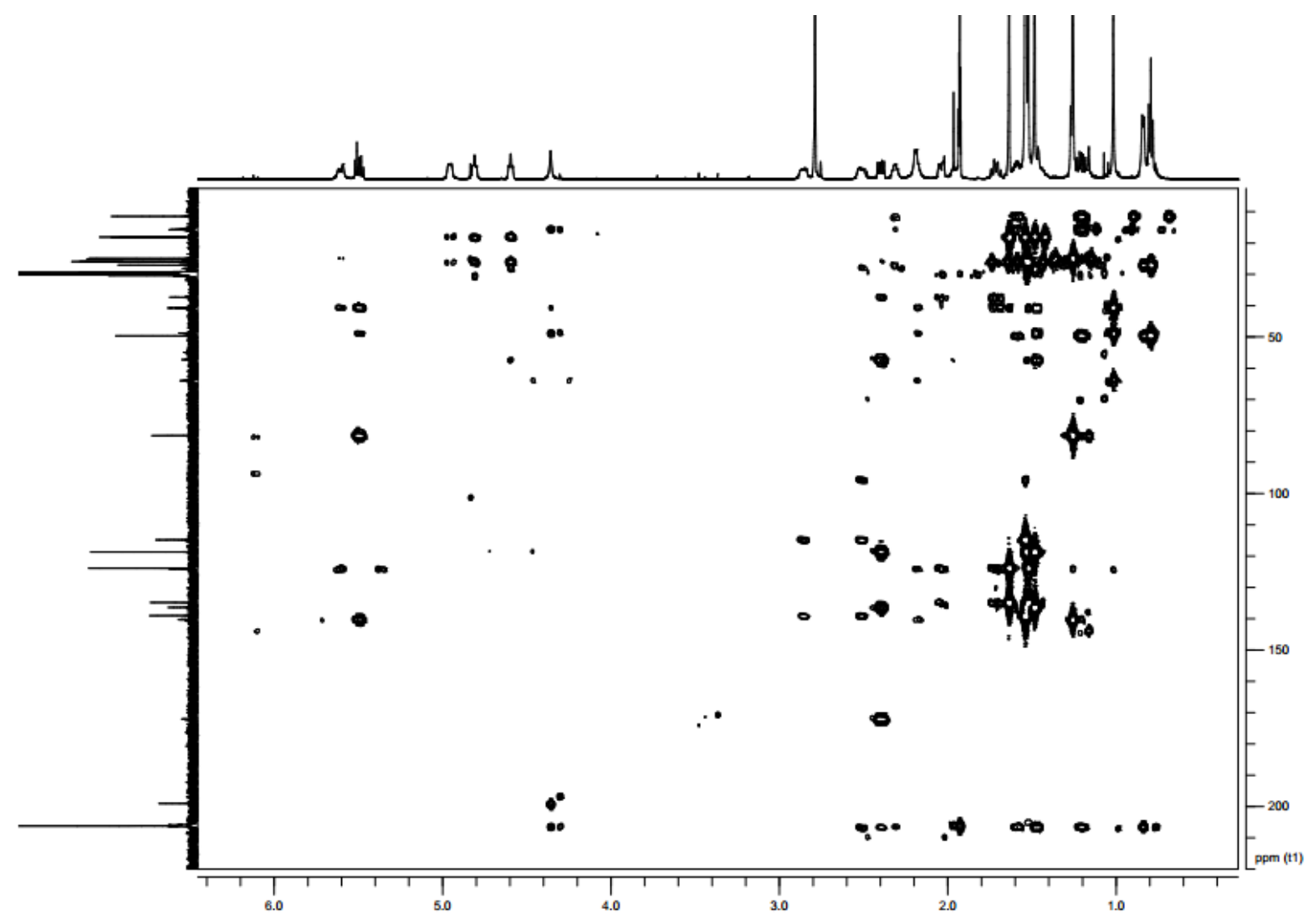

Figure S28. HMBC spectrum of hyperuralone F (4) in acetone- $d_{6}$. 


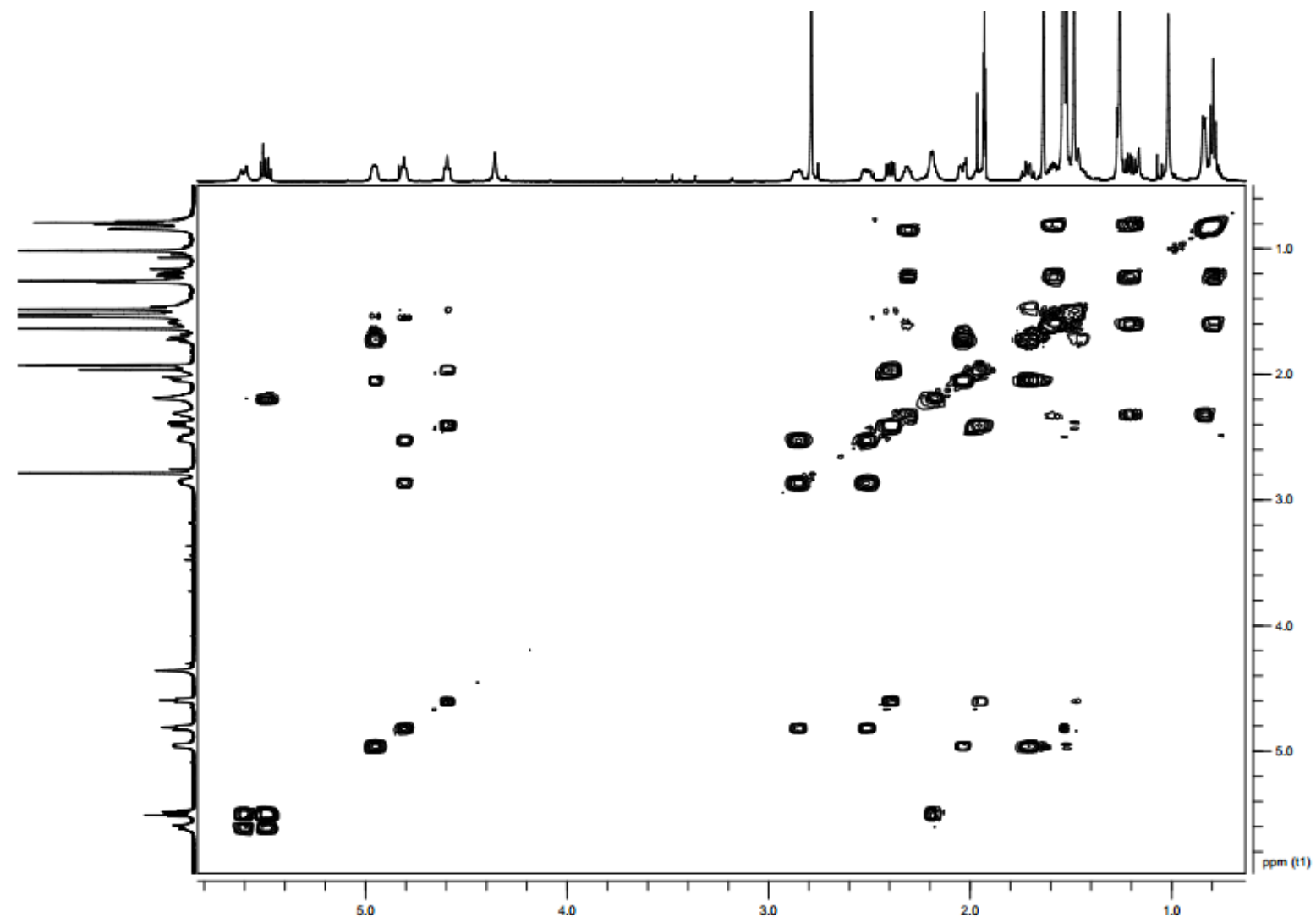

Figure S29. ${ }^{1} \mathrm{H}-{ }^{1} \mathrm{H}$ COSY spectrum of hyperuralone $\mathrm{F}(4)$ in acetone- $d_{6}$.

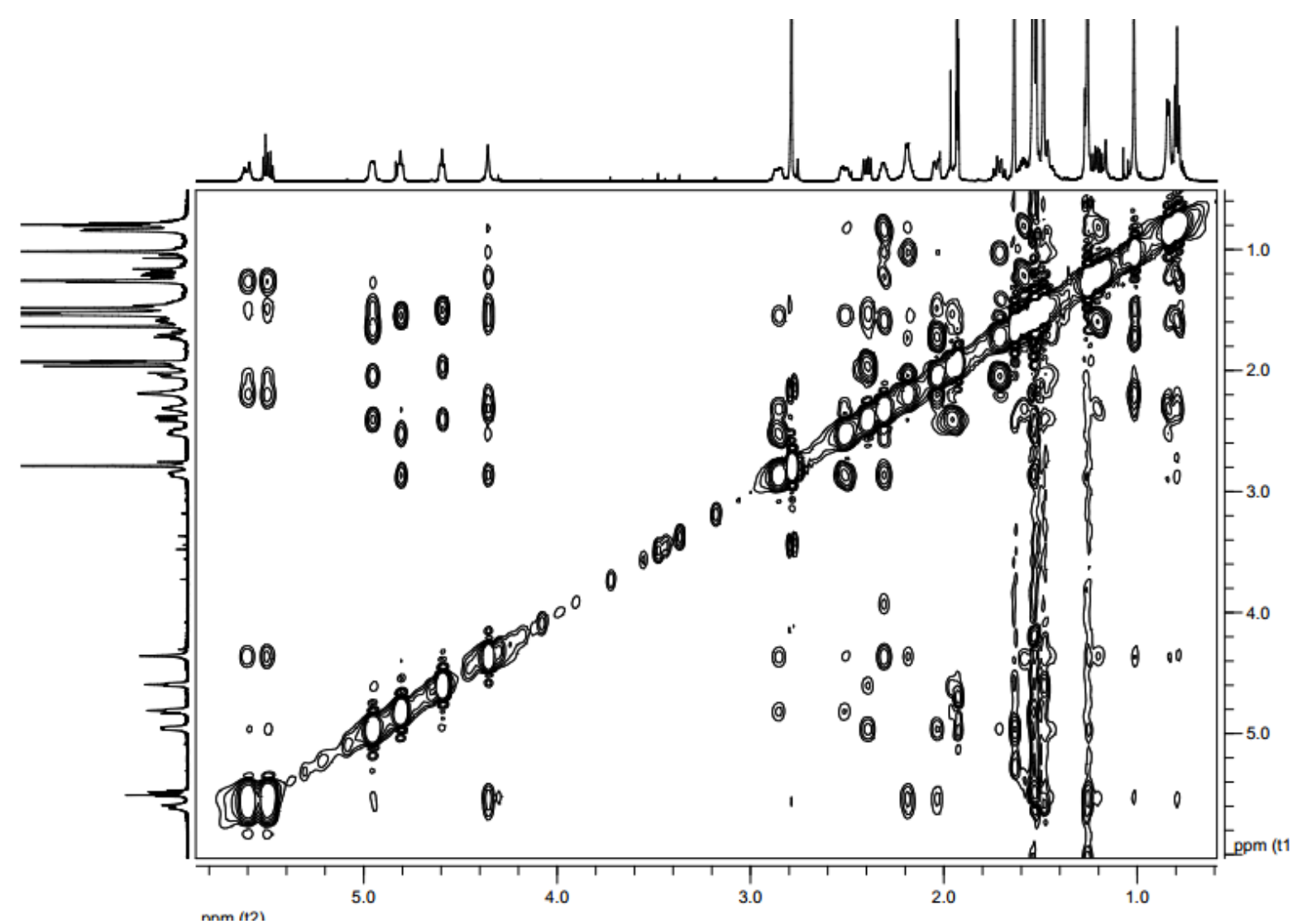

Figure S30. ROESY spectrum of hyperuralone $\mathrm{F}(4)$ in acetone- $d_{6}$. 


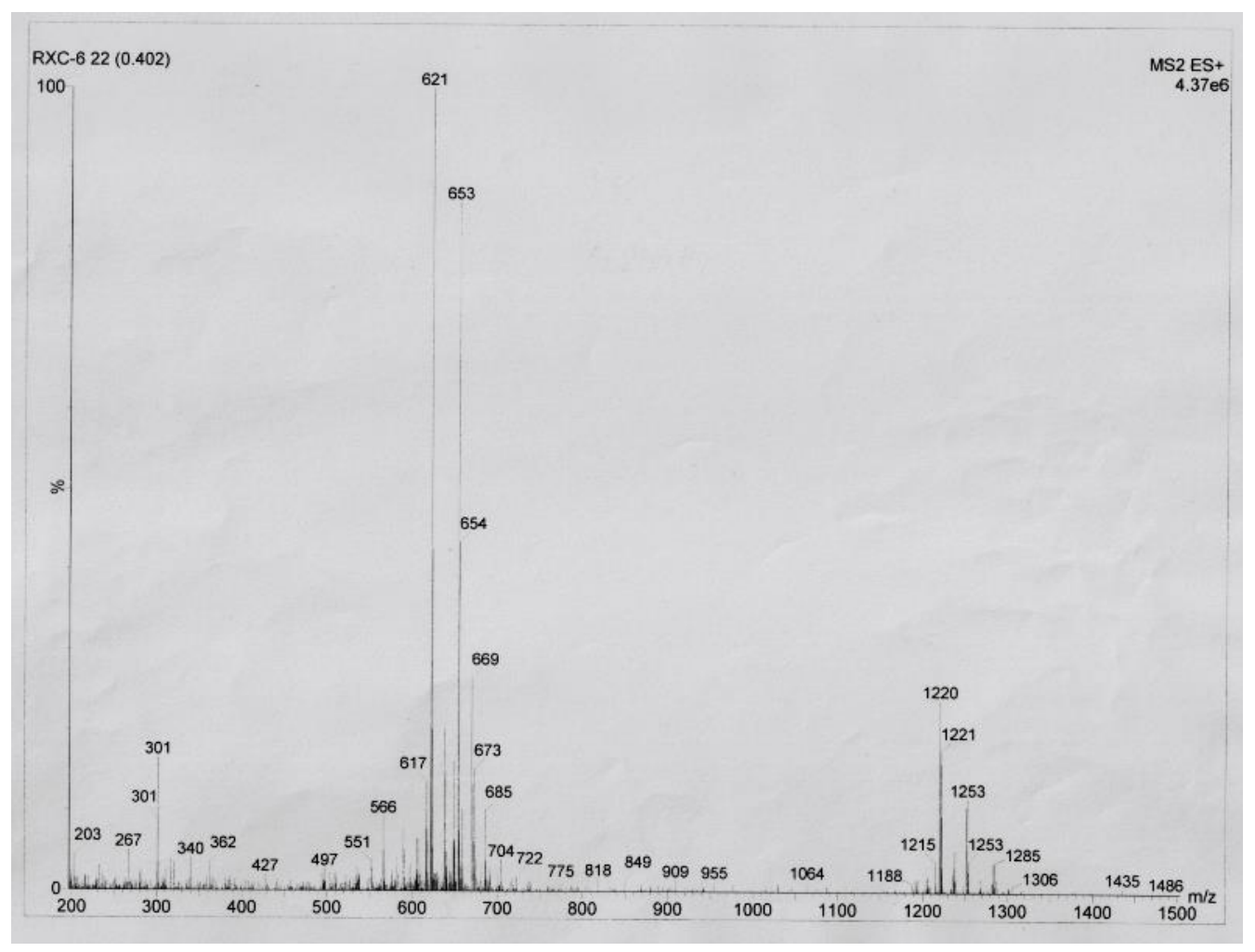

Figure S31. ESIMS spectrum of hyperuralone F (4).

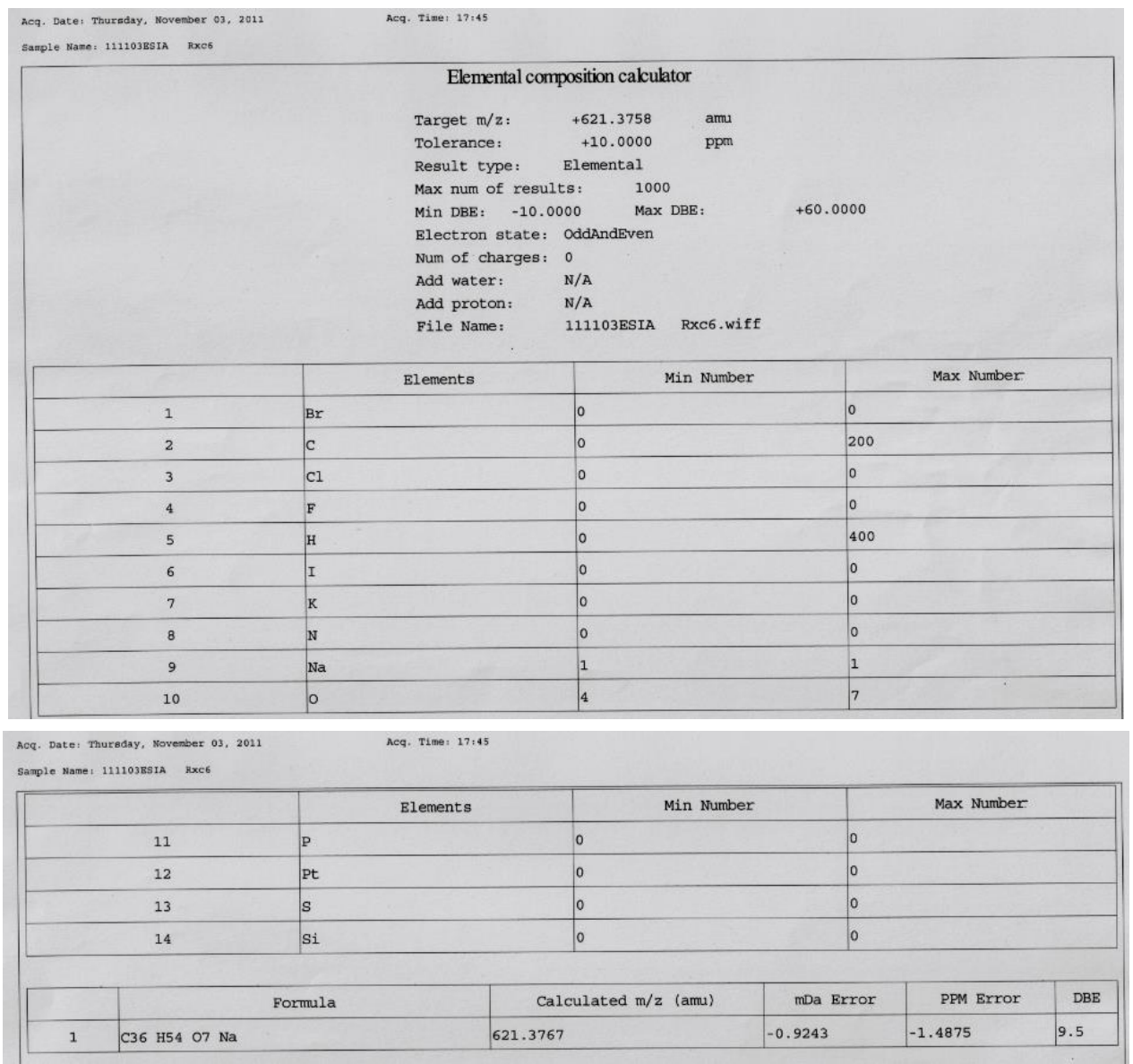

Figure S32. HRTOFMS spectroscopic report of hyperuralone F (4). 


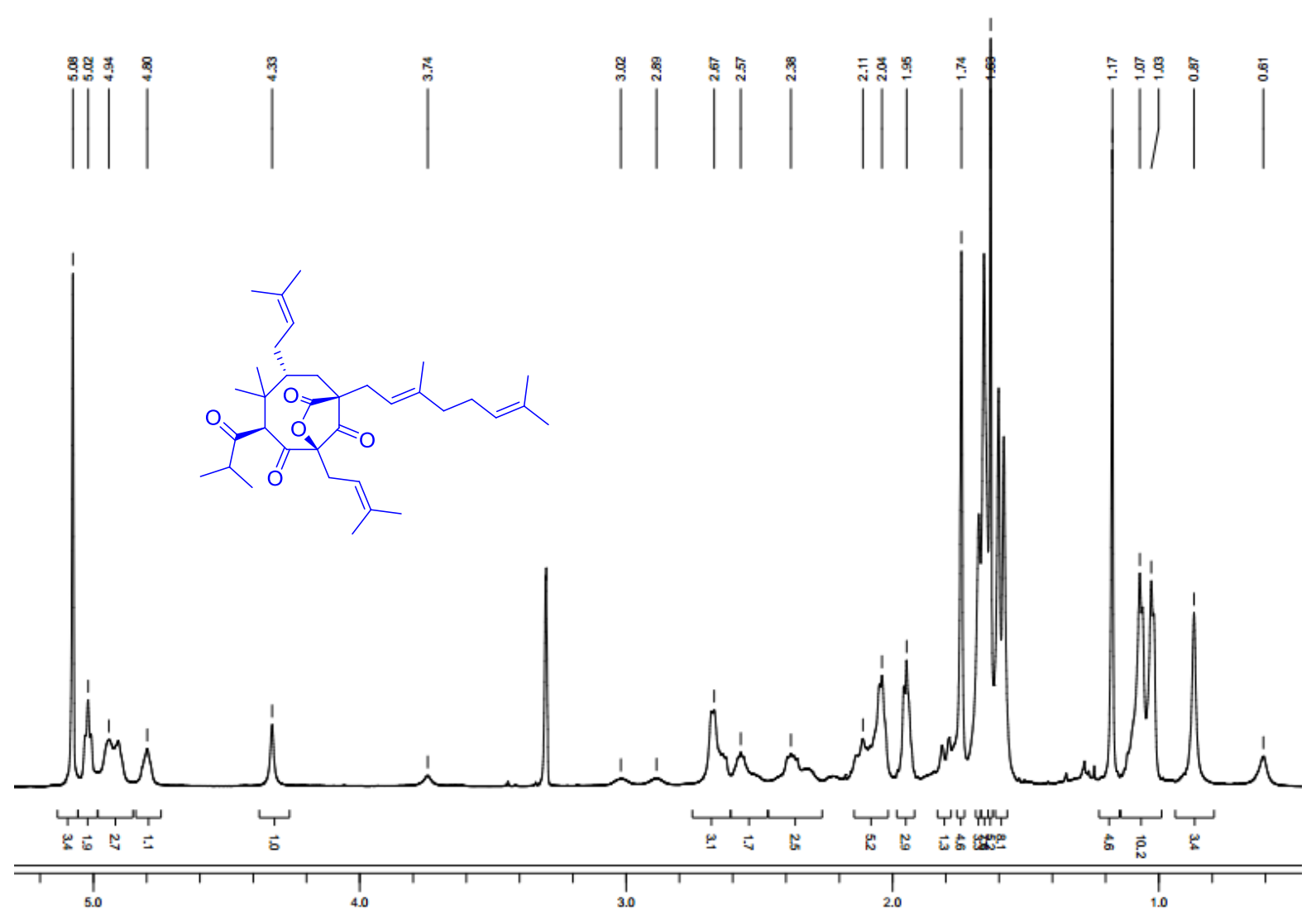

Figure S33. ${ }^{1} \mathrm{H}$ NMR spectrum of hyperuralone G (5) in methanol- $d_{4}$.
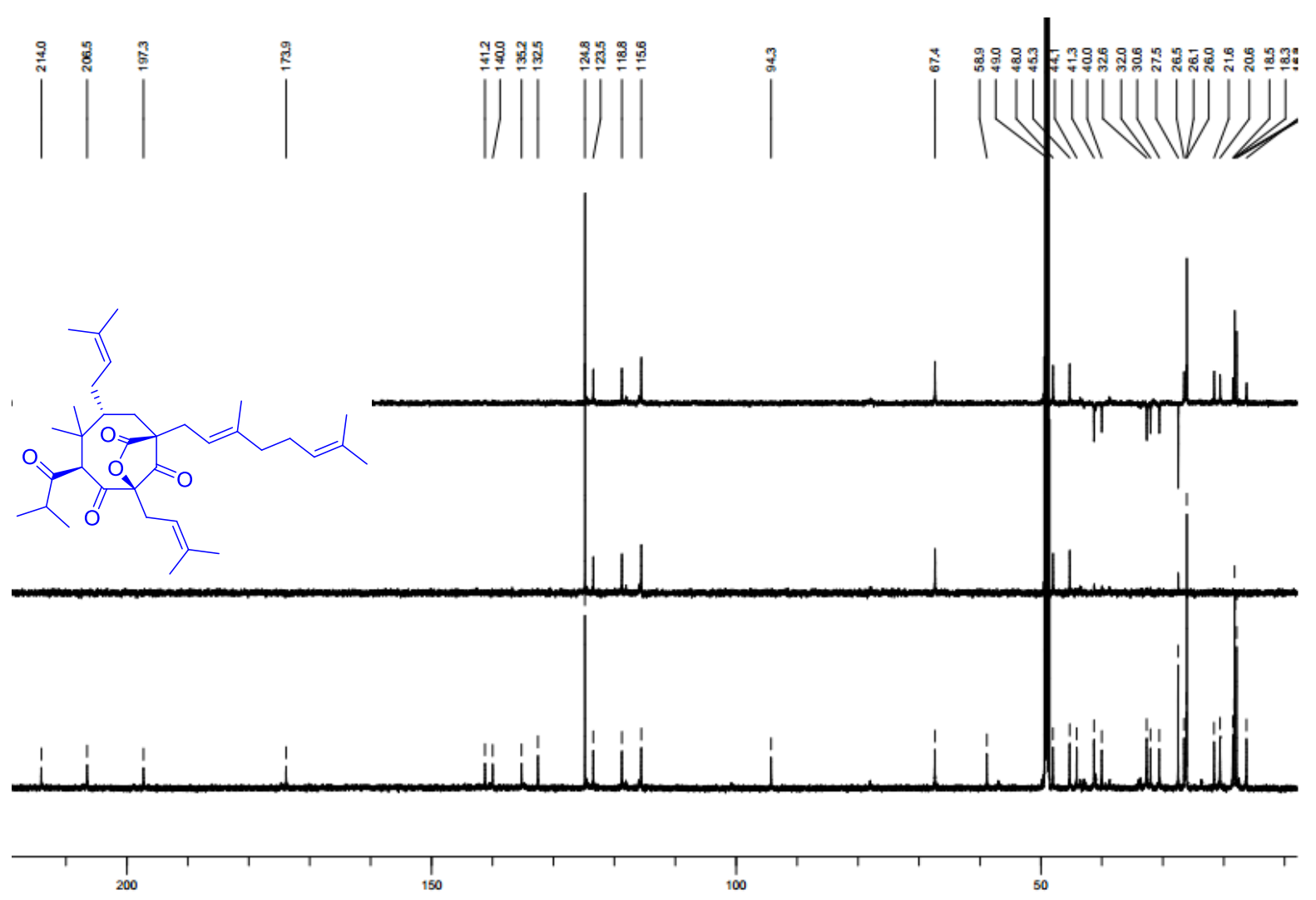

Figure S34. ${ }^{13} \mathrm{C}$ and DEPT NMR spectra of hyperuralone F (4) in methanol- $d_{4}$. 


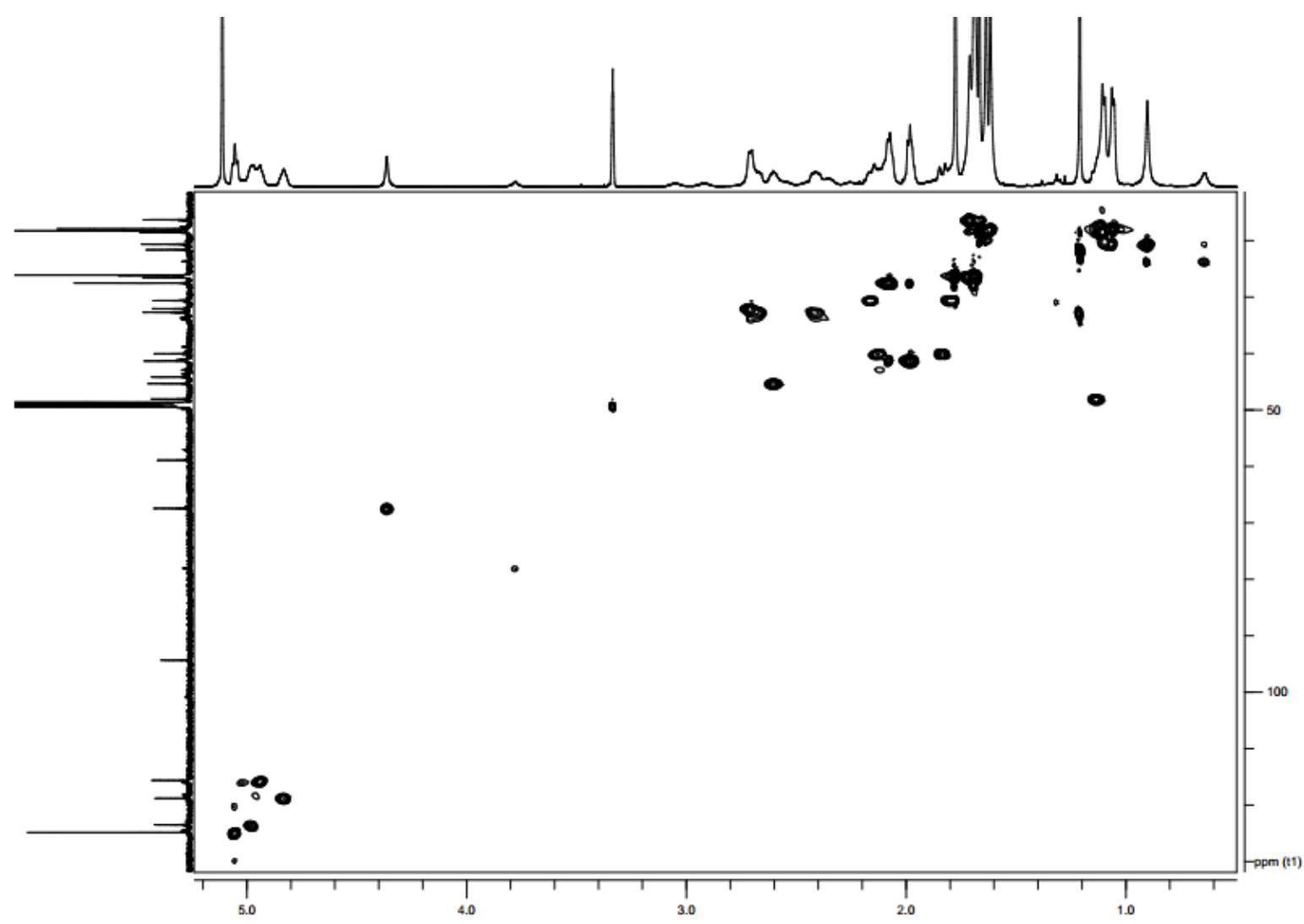

Figure S35. HSQC spectrum of hyperuralone G (5) in methanol- $d_{4}$.

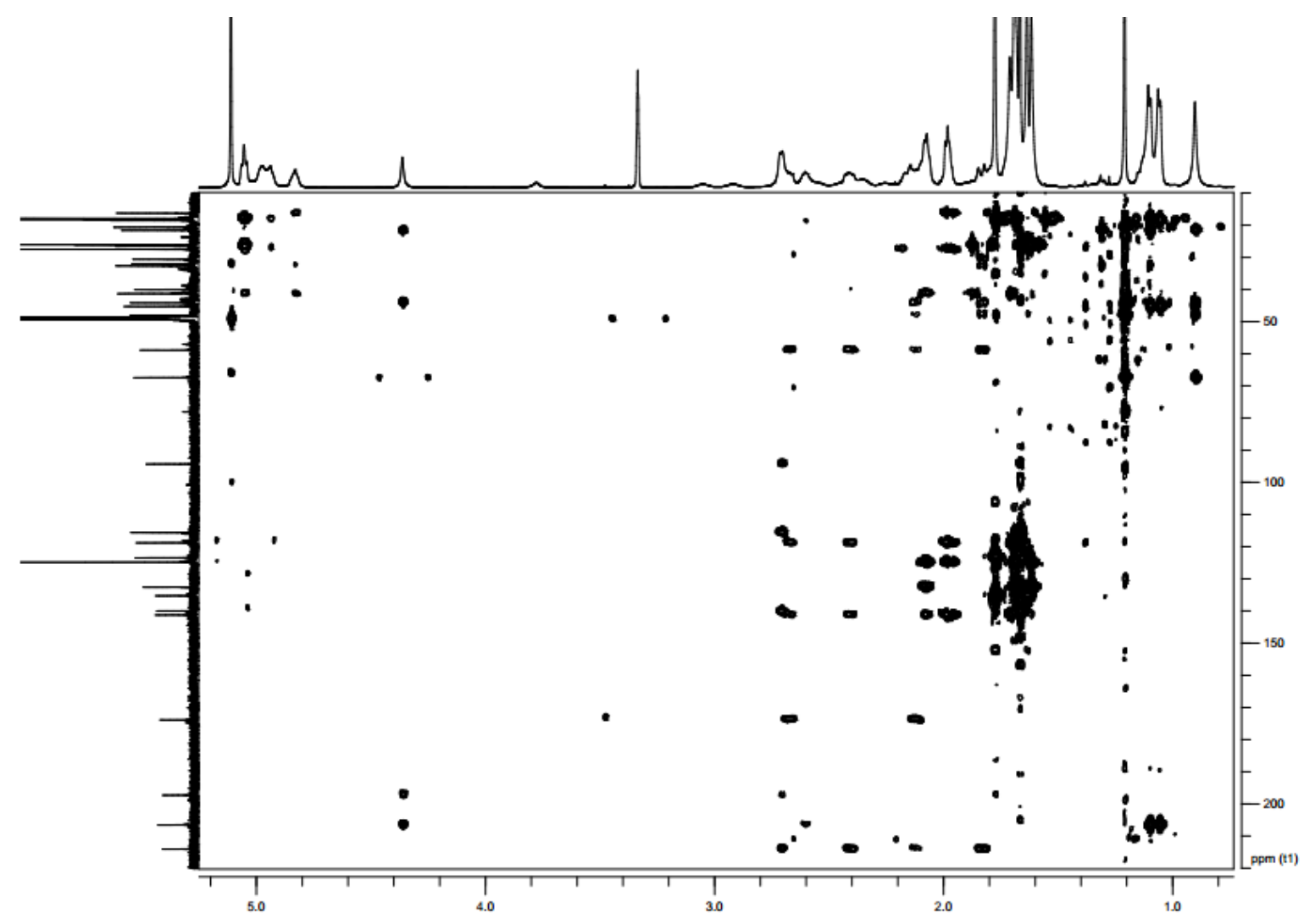

Figure S36. HMBC spectrum of hyperuralone G (5) in methanol- $d_{4}$. 


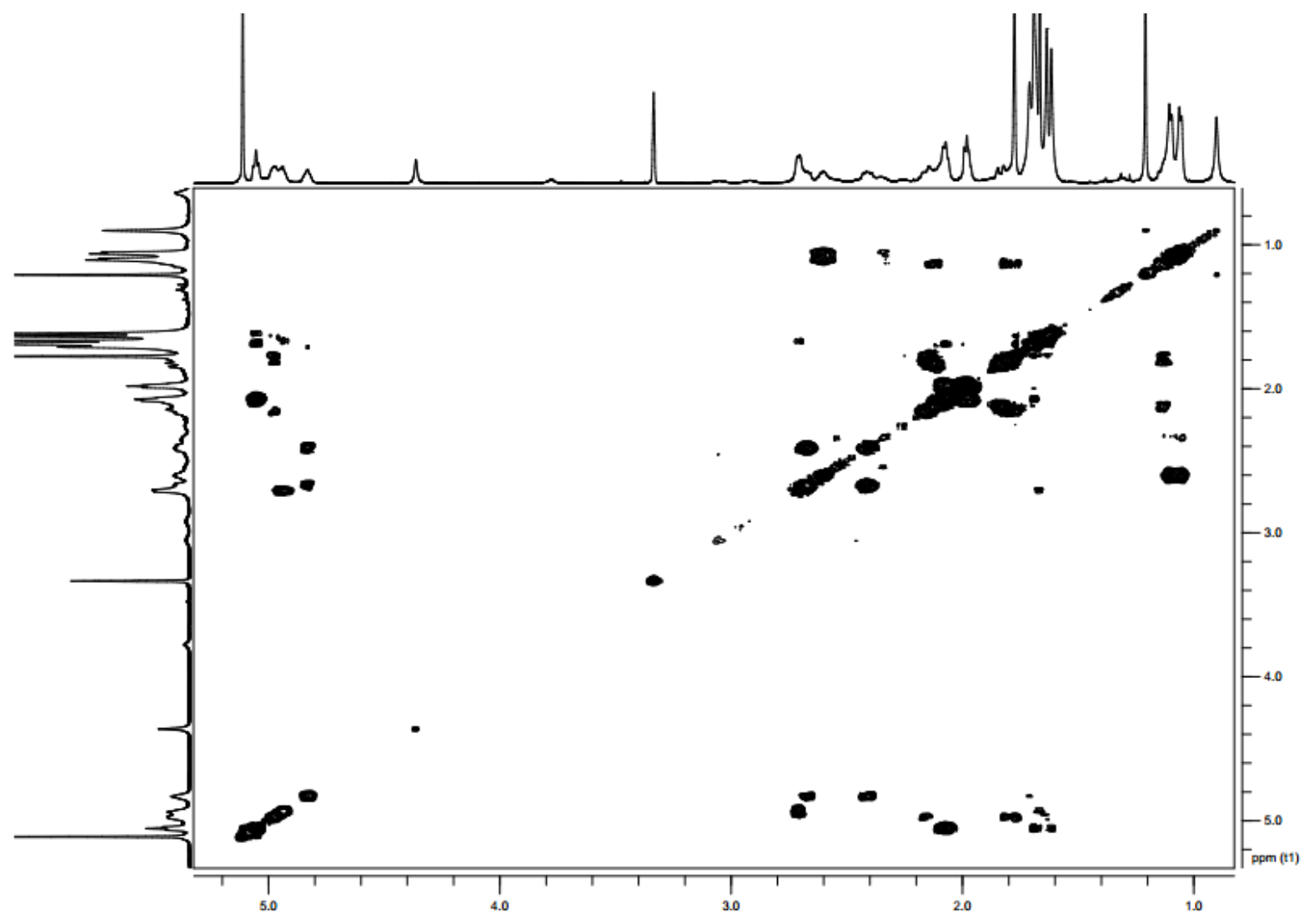

Figure S37. ${ }^{1} \mathrm{H}-{ }^{1} \mathrm{H}$ COSY spectrum of hyperuralone G (5) in methanol- $d_{4}$.

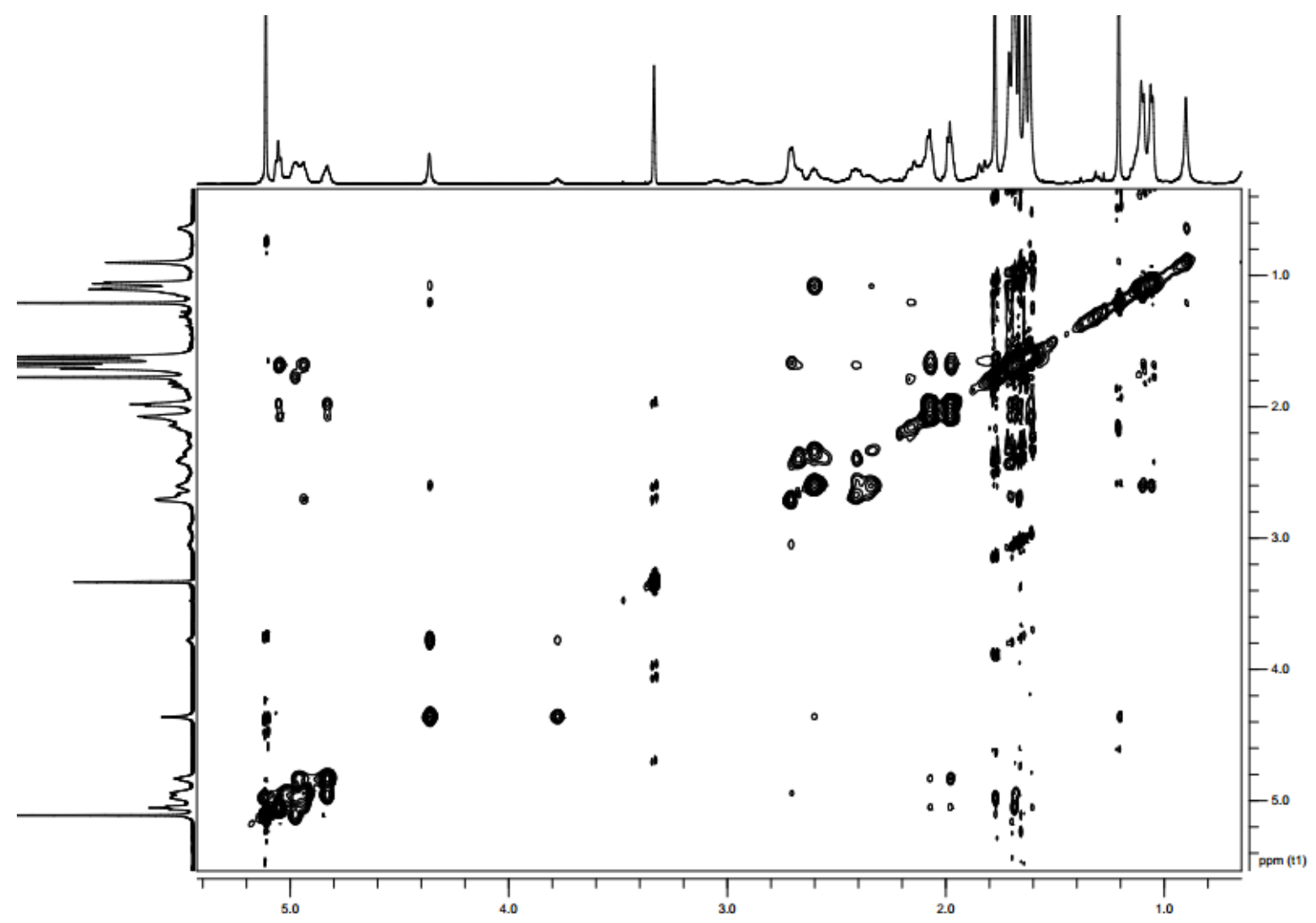

Figure S38. ROESY spectrum of hyperuralone G (5) in methanol- $d_{4}$. 


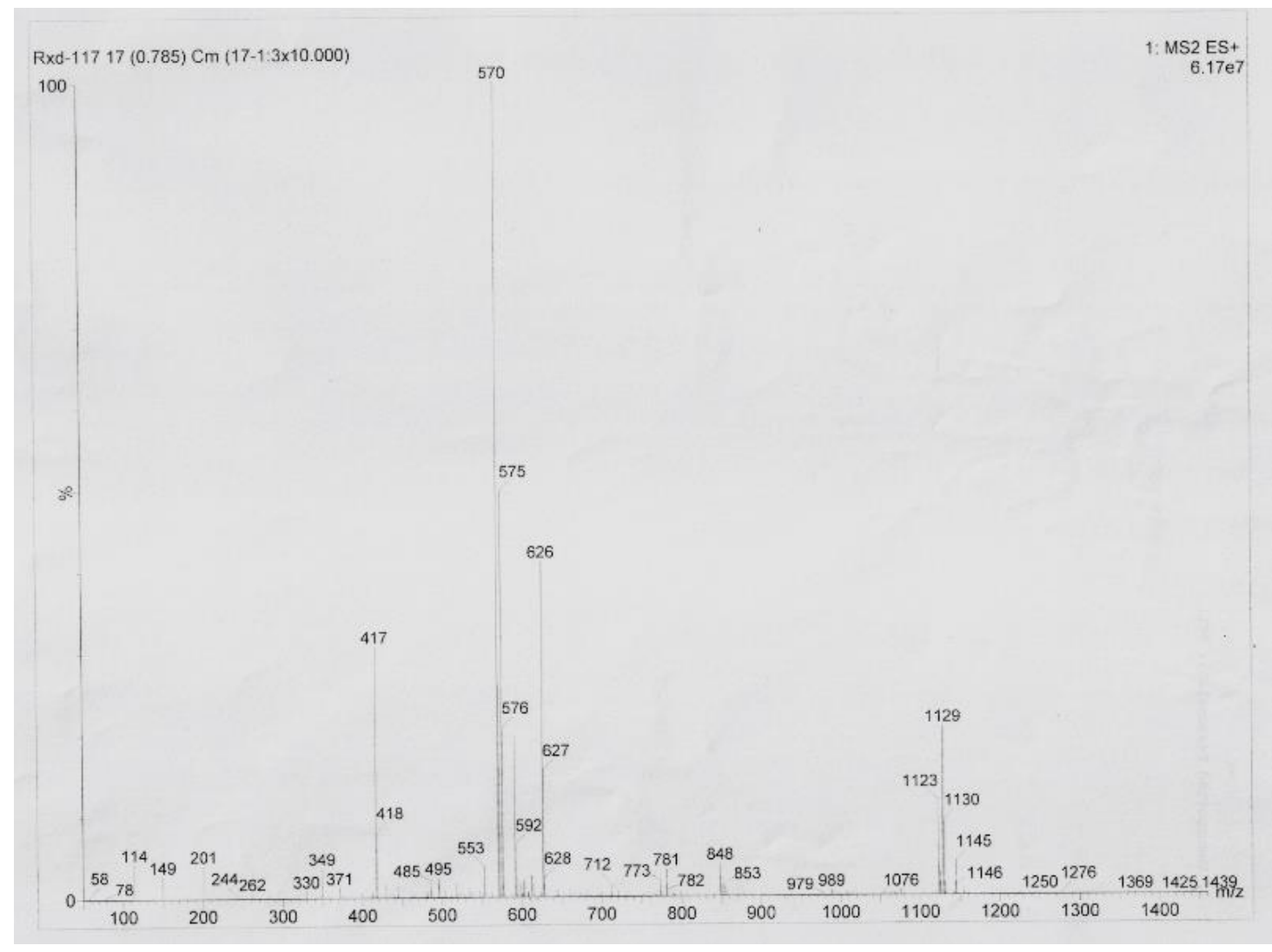

Figure S39. ESIMS spectrum of hyperuralone G (5).

Elemental Composition Report

Single Mass Analysis

Tolerance $=10.0$ PPM / DBE: $\min =-10.0, \max =120.0$

Selected filters: None

Monoisotopic Mass, Odd and Even Electron lons

24 formula(e) evaluated with 1 results within limits (up to 51 closest results for each mass)

C: $0-200$ H: $0-400 \quad 0: 4-6$

Rx:-117 13 08-Apr-2014

Voltage El+ + M140008EA-08AFAMM
552.3831

M140408EA-08AFAMM 28 (2.570)

$\%-$
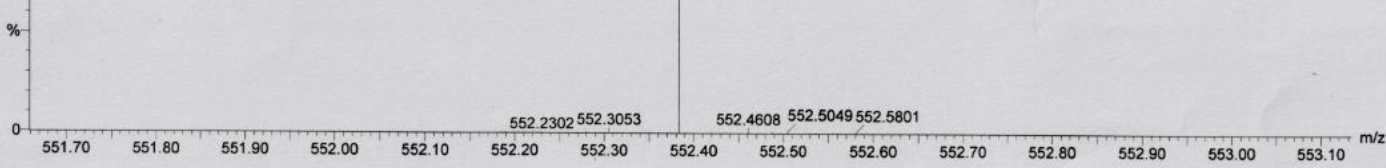

$\begin{array}{llll}\text { Minimum: } & 200.0 & 10.0 & -10.0 \\ \text { Maximum: } & & 120.0\end{array}$

Mass Calc. Mass mDa PPM DBE i-FIT Formula

$\begin{array}{lllllllll}552.3831 & 552.3815 & 1.6 & 2.9 & 10.0 & 5546674.5 & \text { C35 } & \text { H52 } & \text { O5 }\end{array}$

Figure S40. HREIMS spectrum of hyperuralone G (5). 


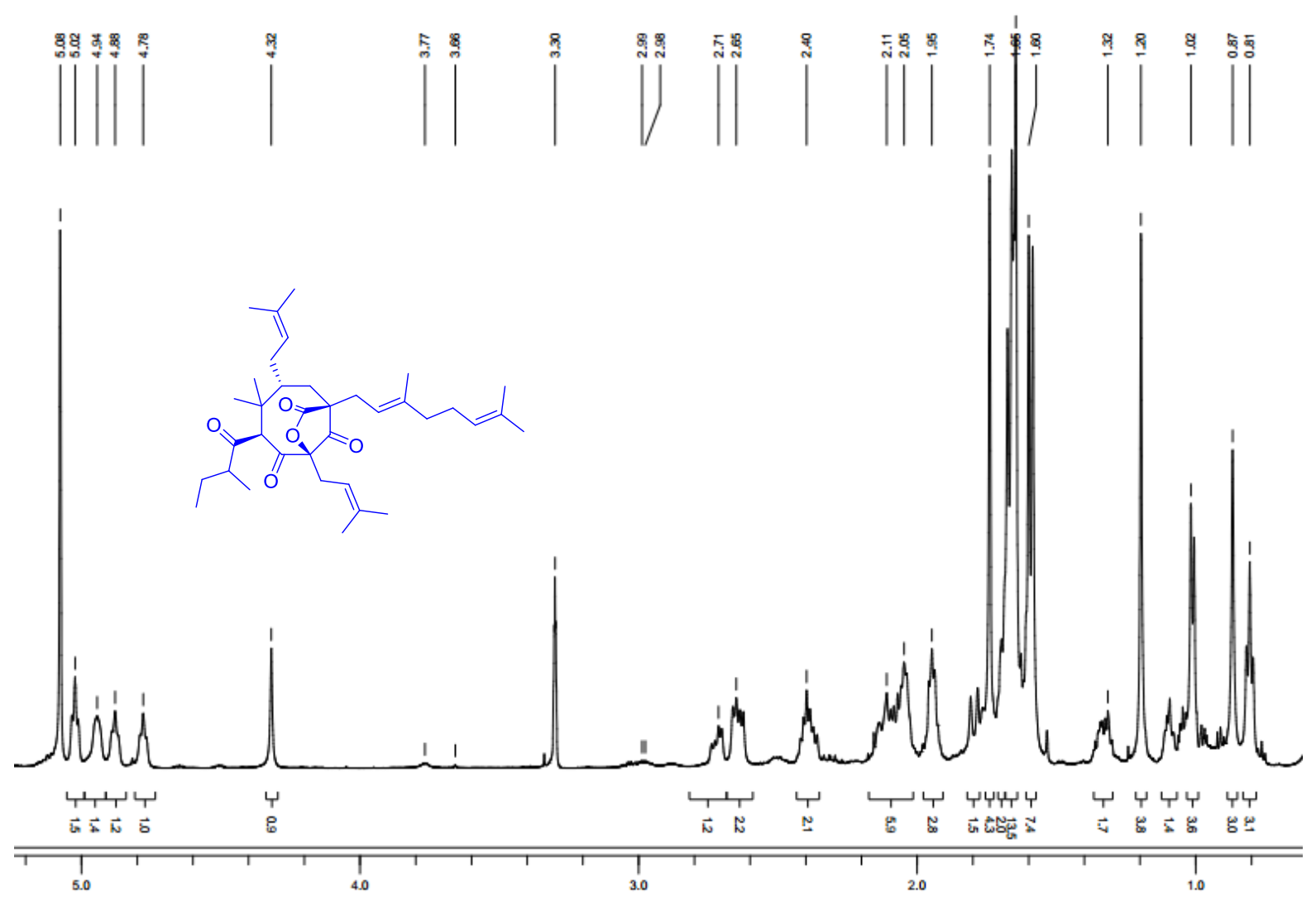

Figure S41. ${ }^{1} \mathrm{H}$ NMR spectrum of hyperuralone H (6) in methanol- $d_{4}$.
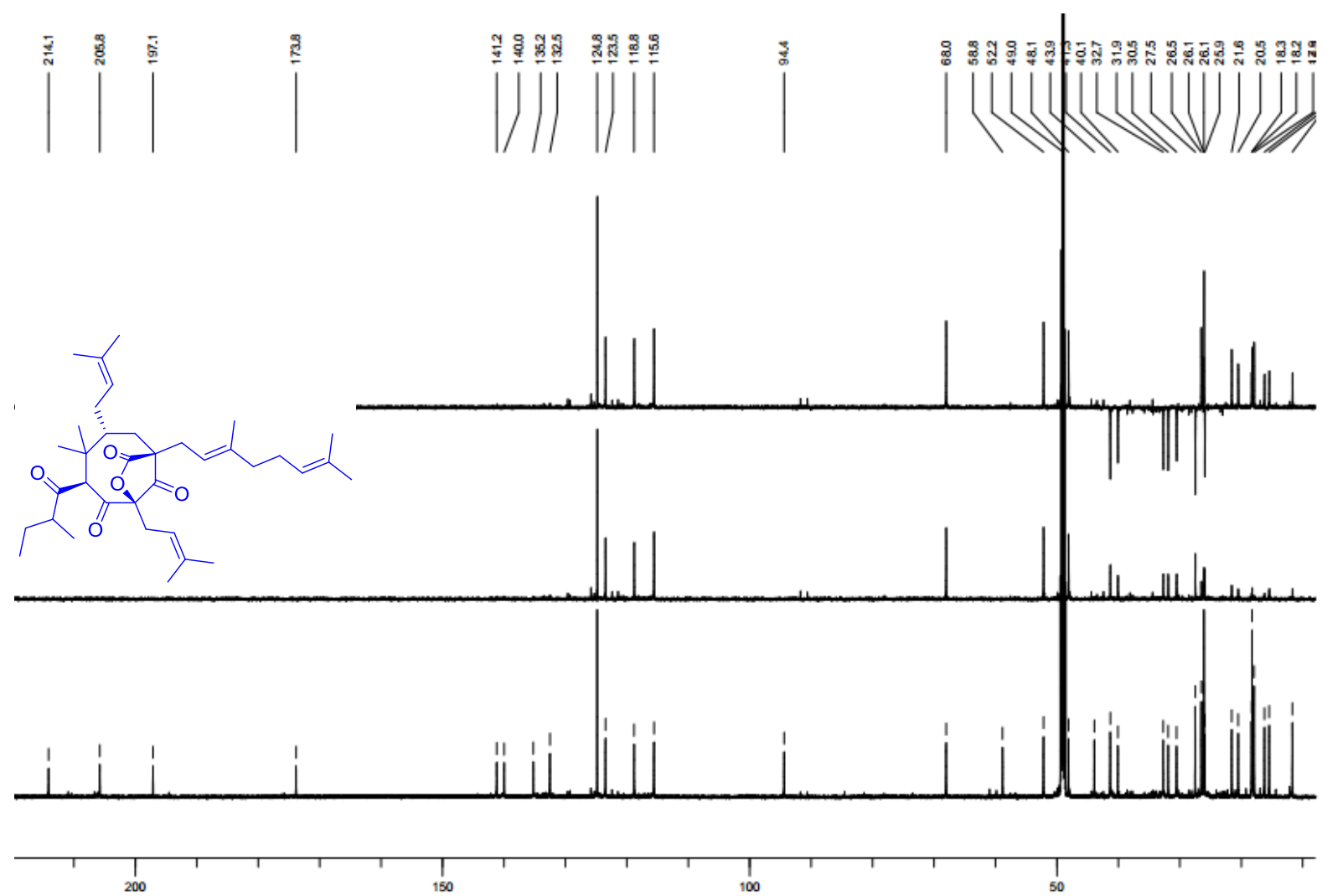

Figure S42. ${ }^{13} \mathrm{C}$ and DEPT NMR spectra of hyperuralone $\mathrm{H}(\mathbf{5})$ in methanol- $d_{4}$. 


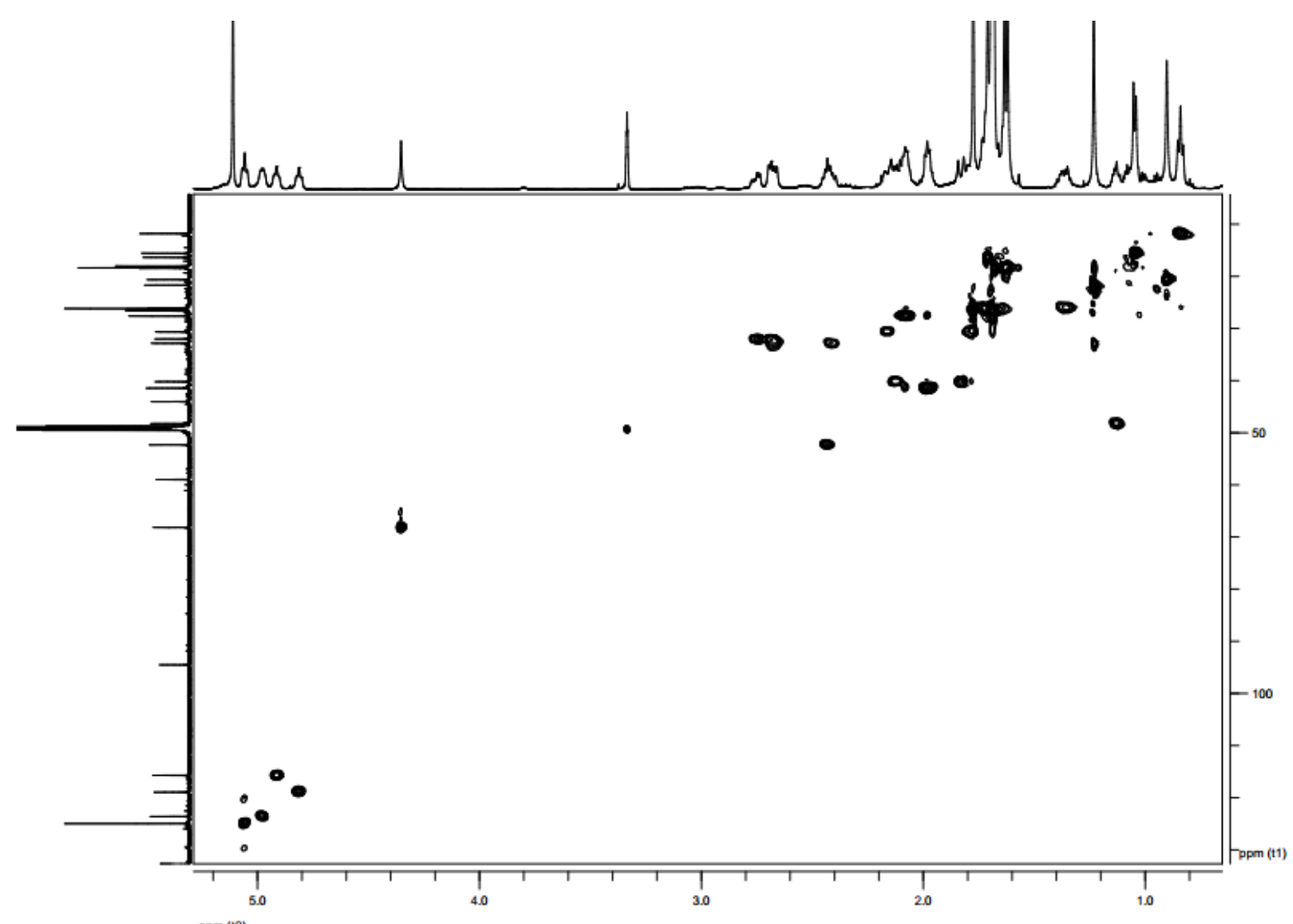

Figure S43. HSQC spectrum of hyperuralone H (6) in methanol- $d_{4}$.

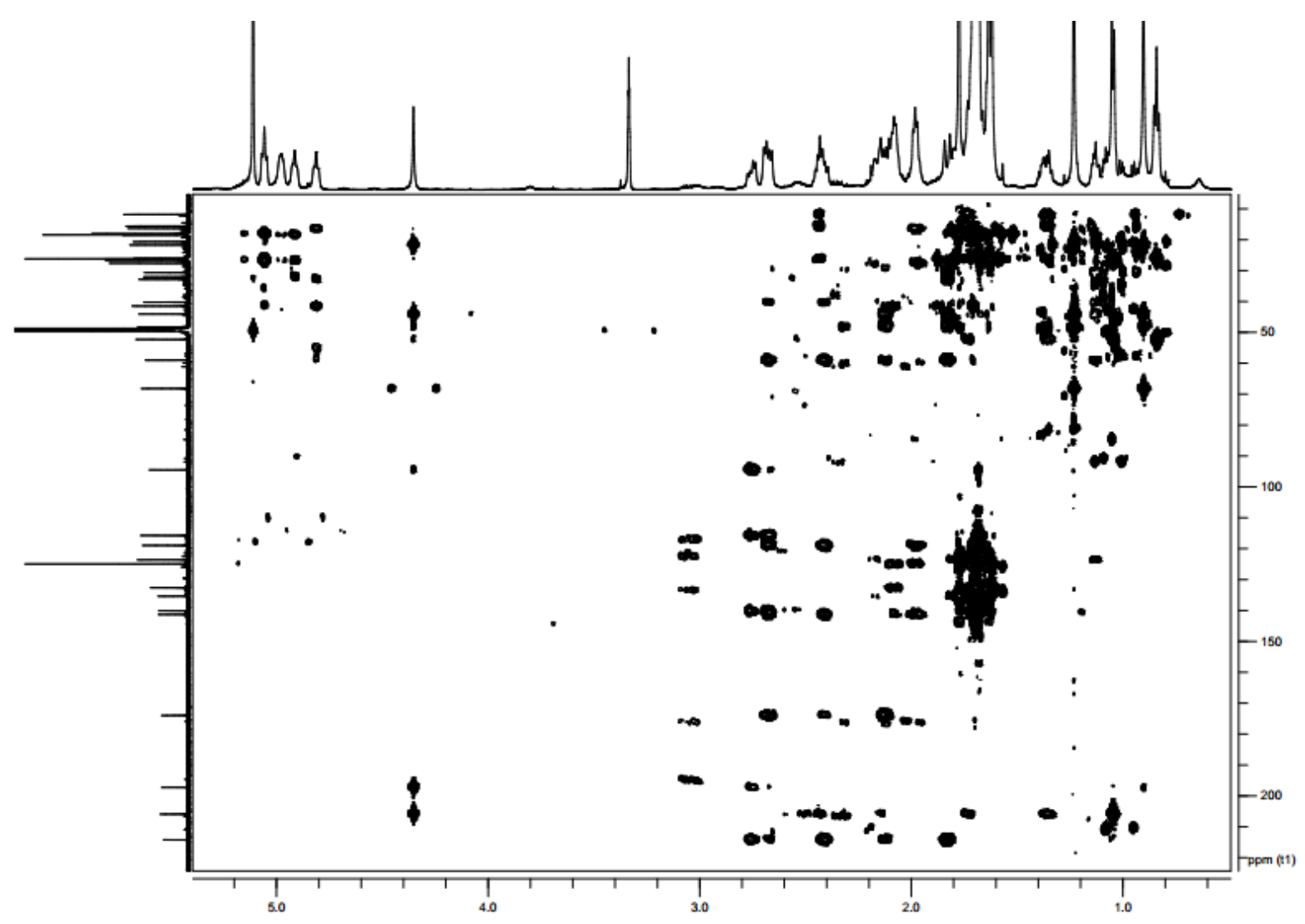

Figure S44. HMBC spectrum of hyperuralone H (6) in methanol- $d_{4}$. 


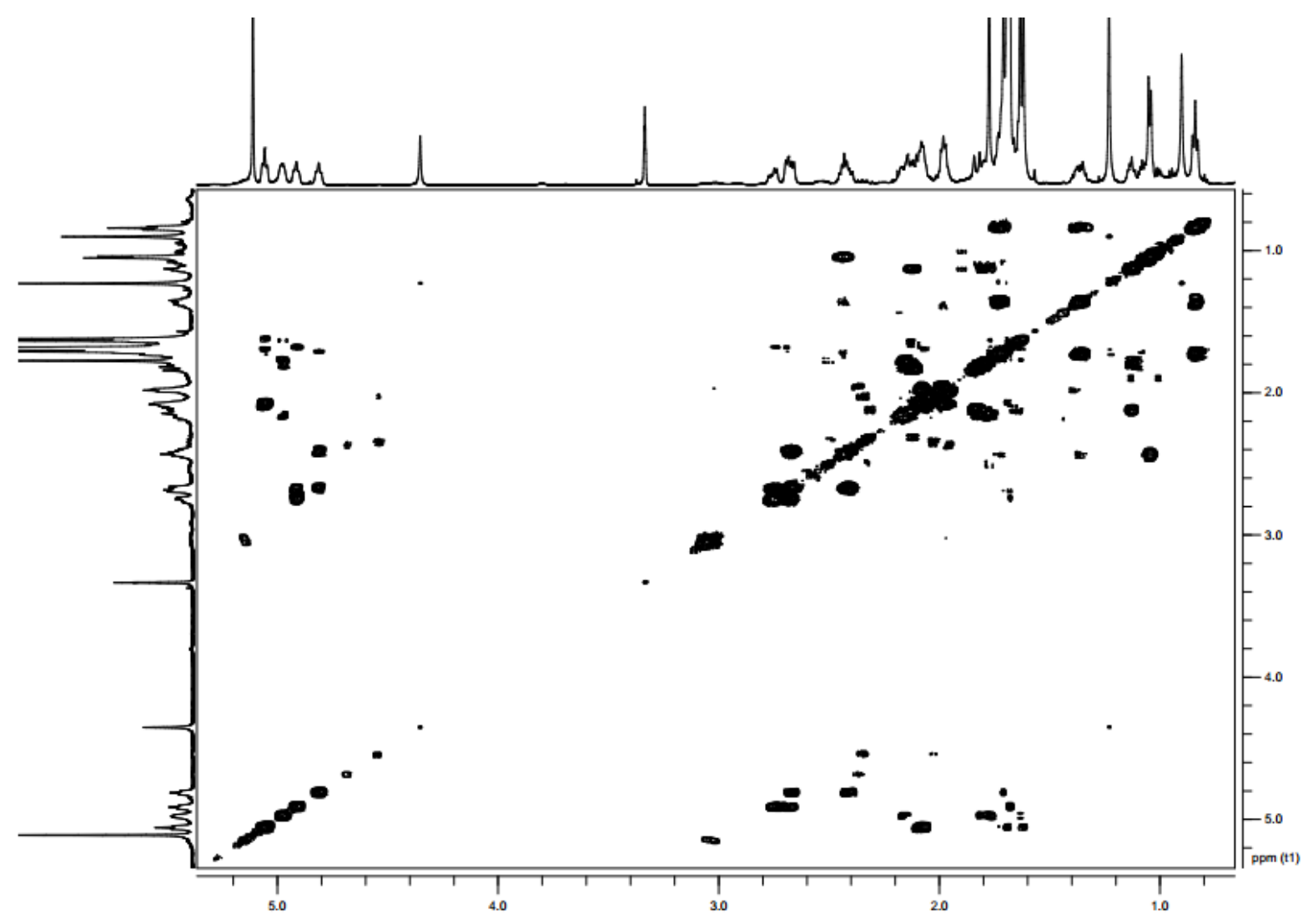

Figure S45. ${ }^{1} \mathrm{H}-{ }^{1} \mathrm{H}$ COSY spectrum of hyperuralone $\mathrm{H}(6)$ in methanol- $d_{4}$.

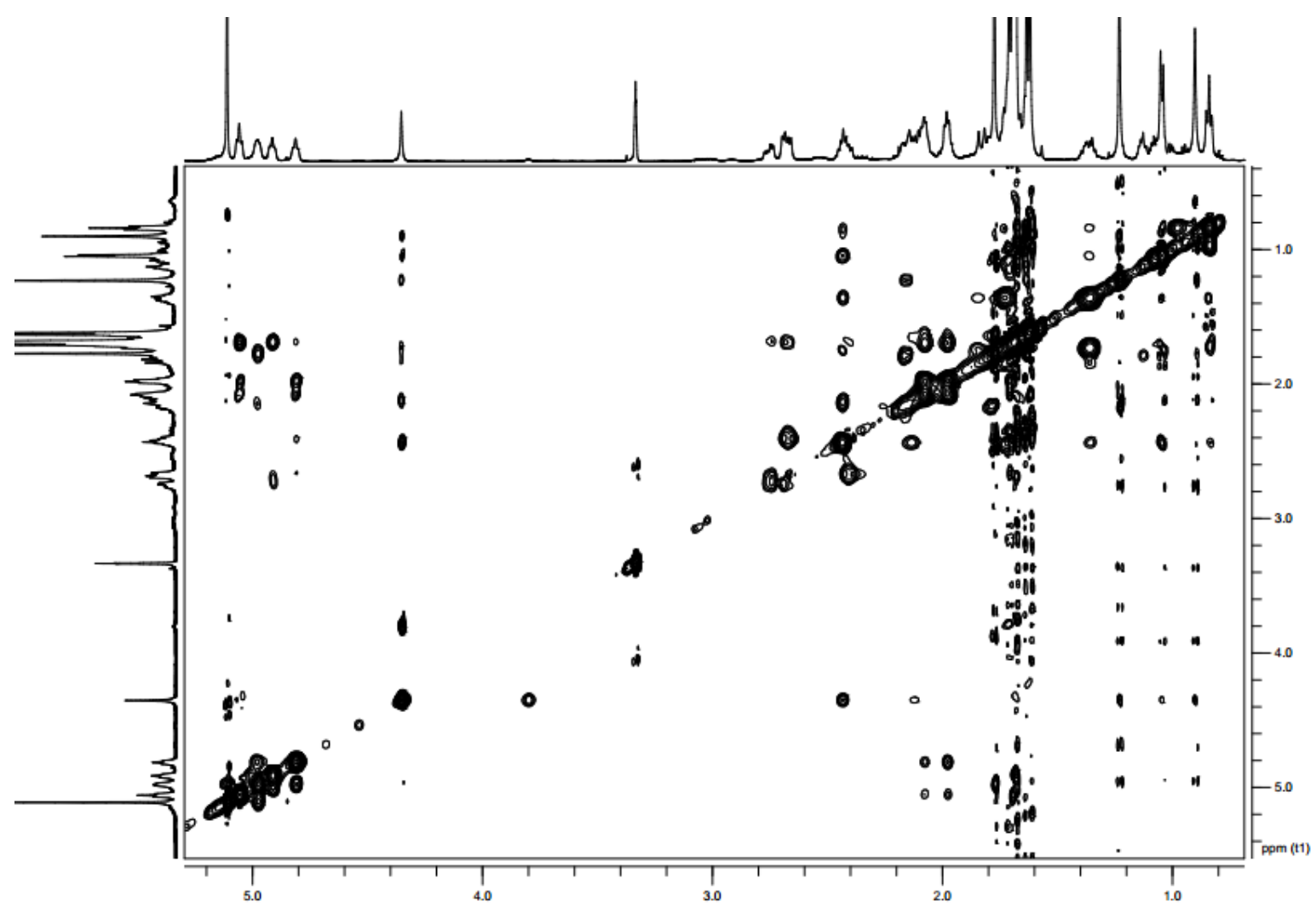

Figure S46. ROESY spectrum of hyperuralone H (6) in methanol- $d_{4}$. 


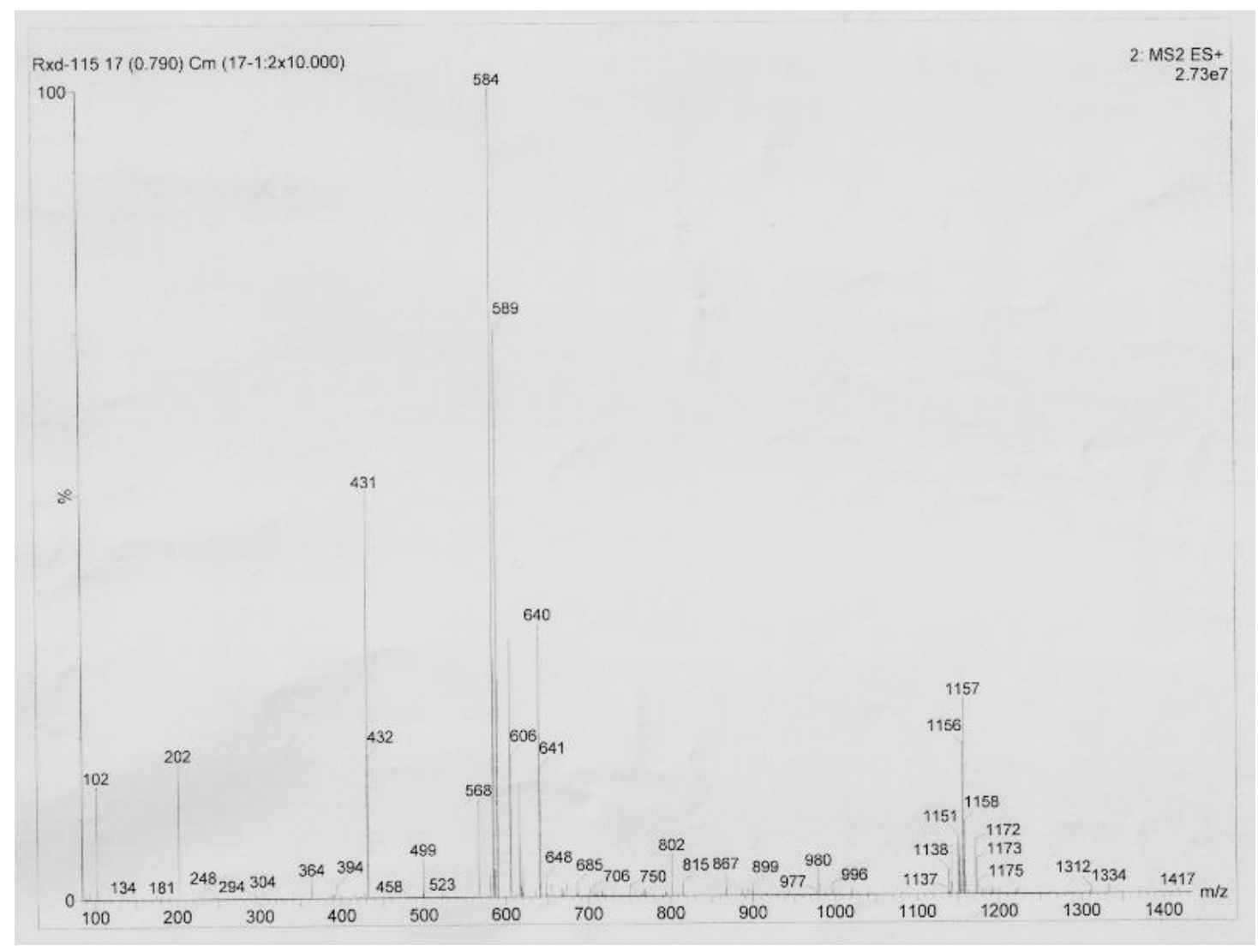

Figure S47. ESIMS spectrum of hyperuralone H (6).

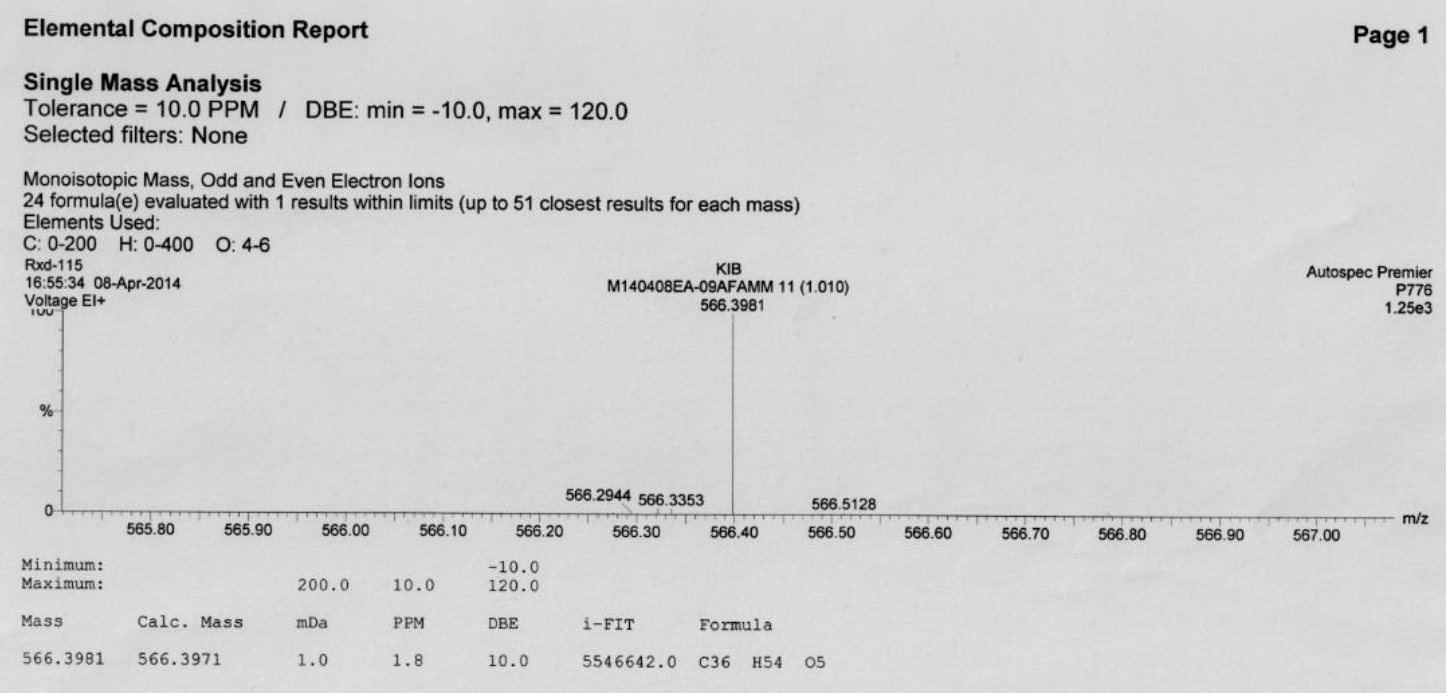

Figure S48. HREIMS spectrum of hyperuralone H (6). 


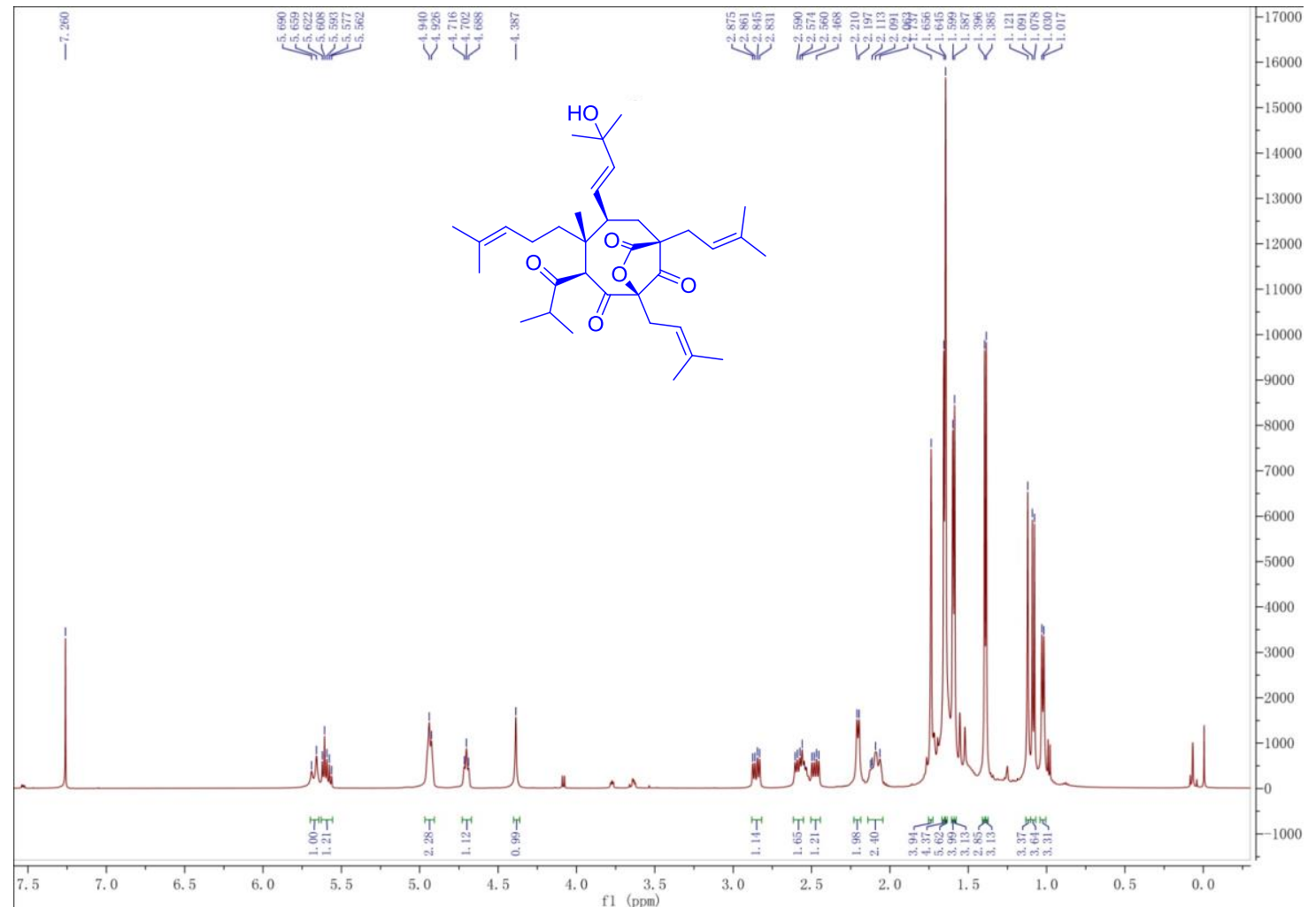

Figure S49. ${ }^{1} \mathrm{H}$ NMR spectrum of attenuatumione B given in Fitoterapia 2014, 95, 1-7.

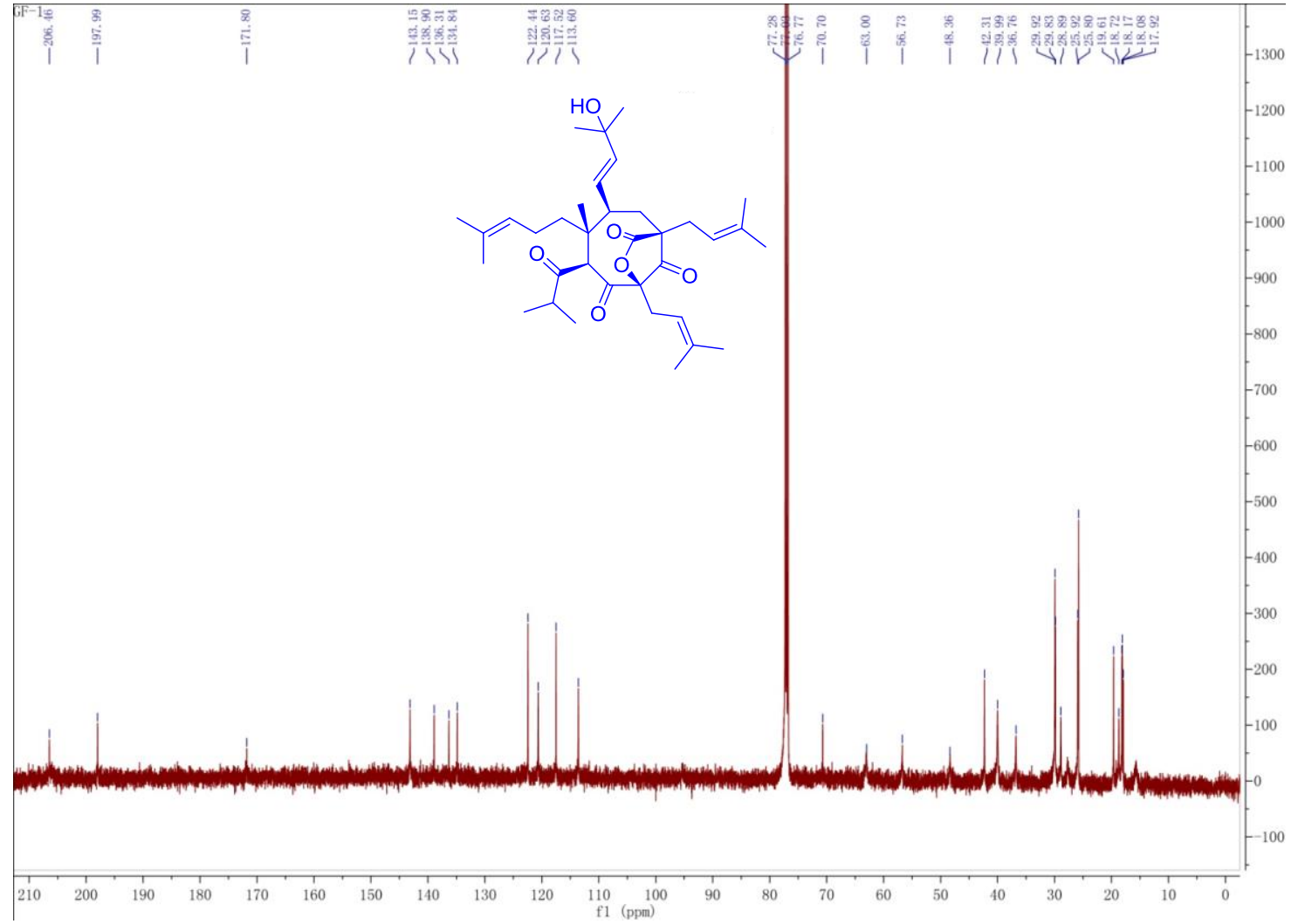

Figure S50. ${ }^{13} \mathrm{C}$ NMR spectrum of attenuatumione B given in Fitoterapia 2014, 95, 1-7. 


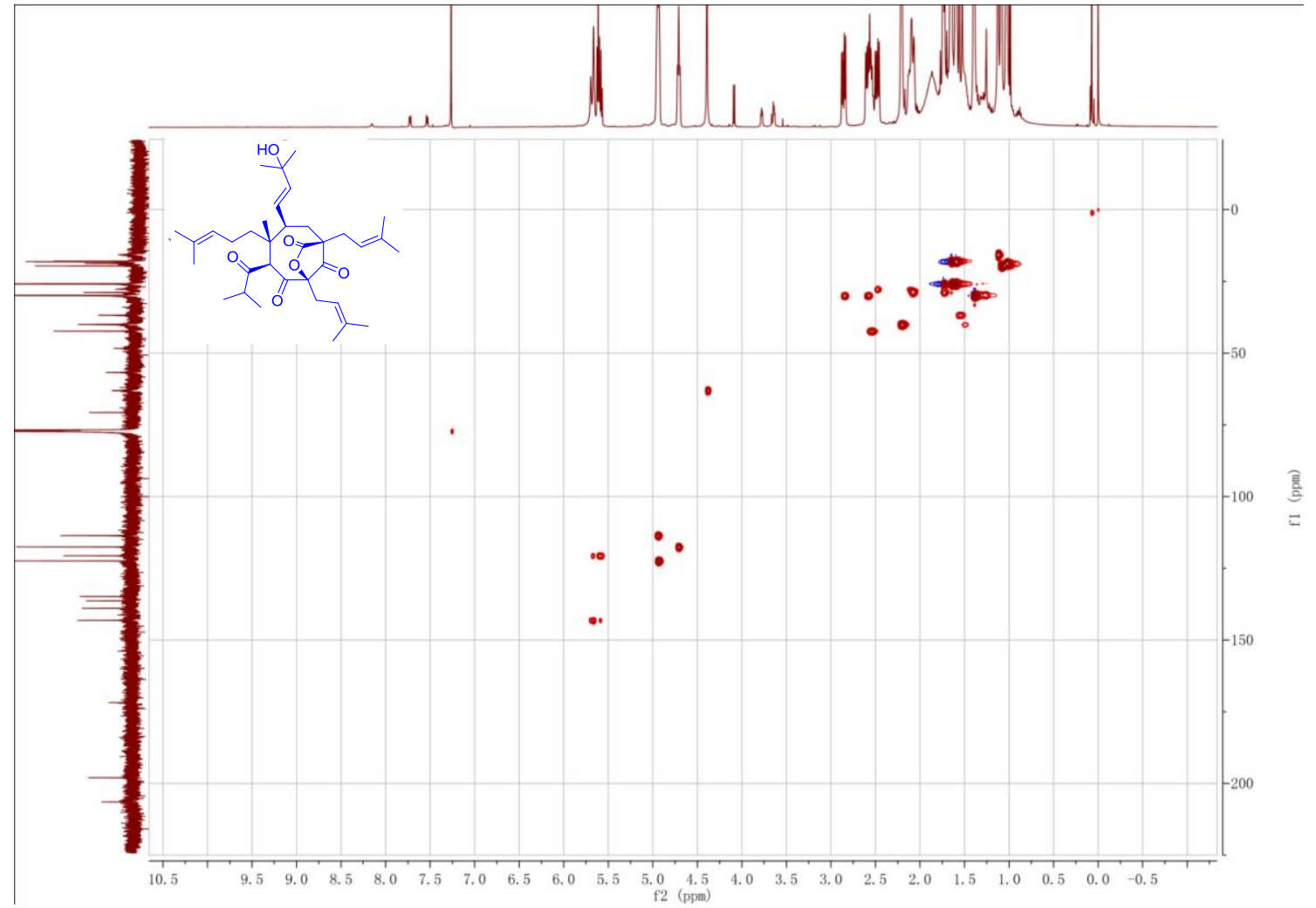

Figure S51. HSQC spectrum of attenuatumione B given in Fitoterapia 2014, 95, 1-7.

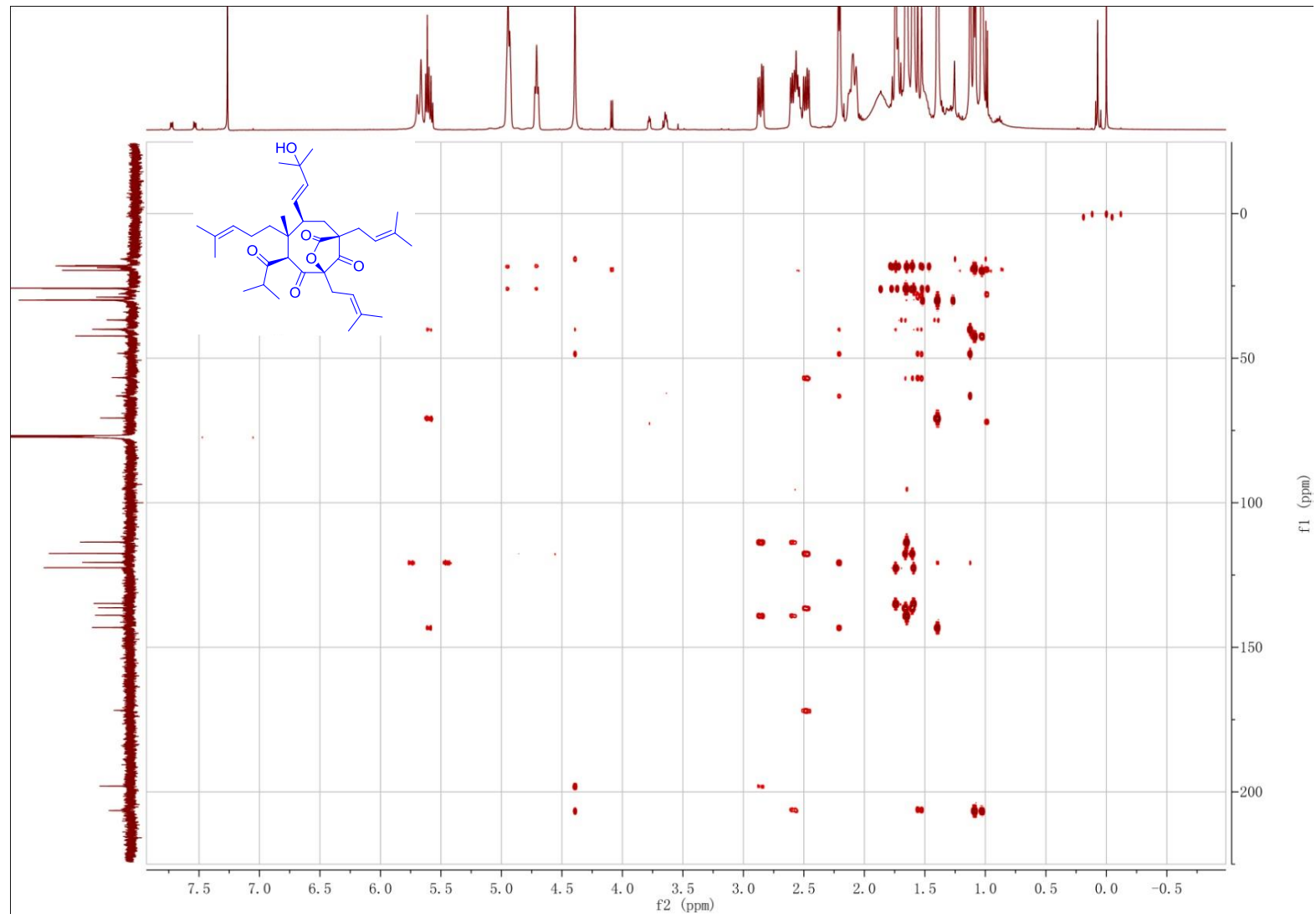

Figure S52. HMBC spectrum of attenuatumione B given in Fitoterapia 2014, 95, 1-7. 


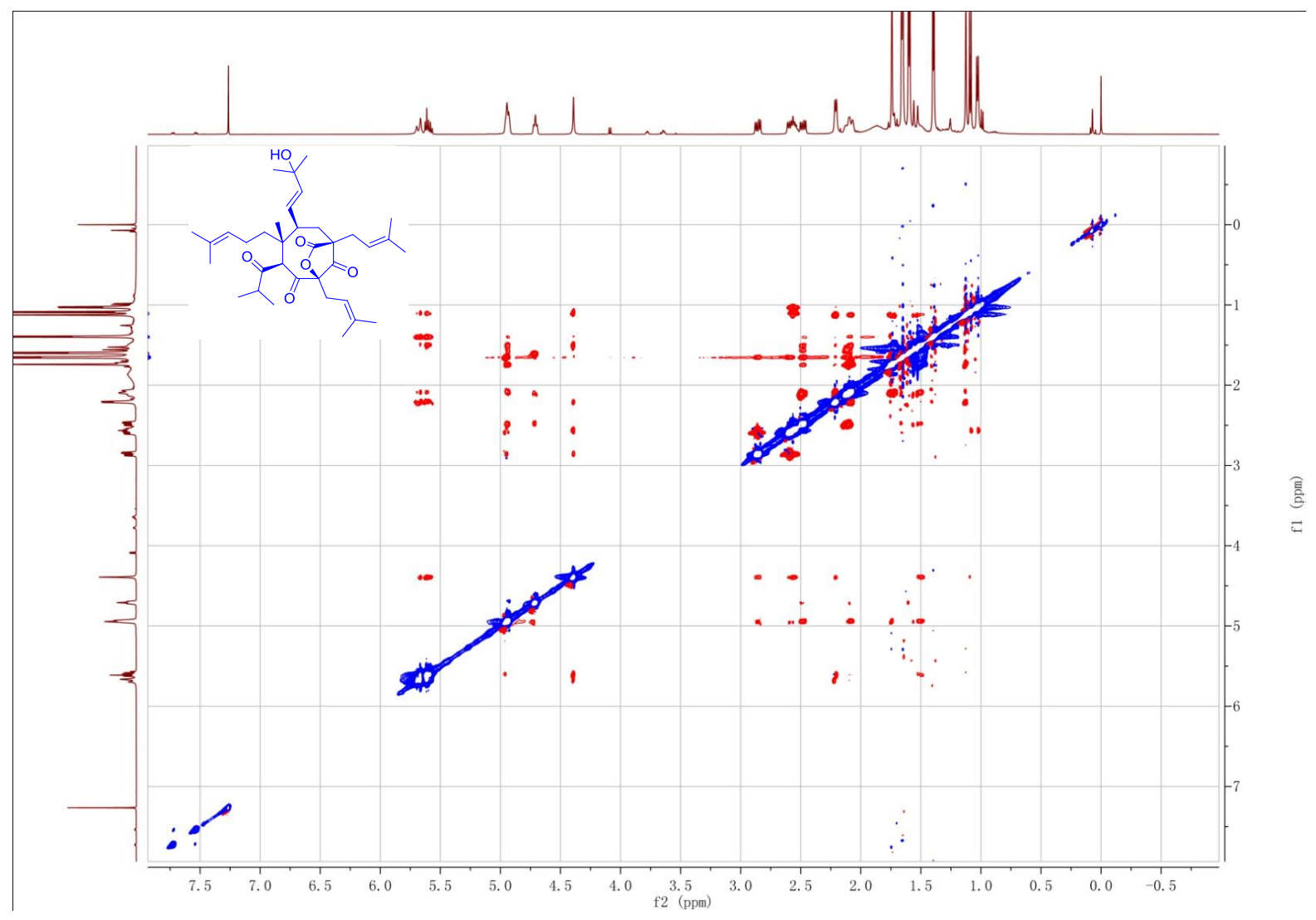

Figure S53. ROESY spectrum of attenuatumione B given in Fitoterapia 2014, 95, 1-7. 